CANCER WORRY INTERFERENCE AND HEALTH SERVICE UTILIZATION IN WOMEN WITH LYNCH SYNDROME: THE ROLE OF TRUSTING ONE’S PHYSICIAN

$$
\text { by }
$$

Lindsey A. Torbit B.A.,

McGill University, 2008

\begin{abstract}
A Thesis presented to Ryerson University
In partial fulfillment of the requirements for the degree of

Master of Arts in the Program of Psychology
\end{abstract}

Toronto, Ontario, Canada, 2013

(C) Lindsey. A Torbit, 2013 


\section{AUTHOR'S DECLARATION FOR ELECTRONIC SUBMISSION OF A THESIS}

I hereby declare that I am the sole author of this thesis. This is a true copy of the thesis, including any required final revisions, as accepted by my examiners.

I authorize Ryerson University to lend this thesis to other institutions or individuals for the purpose of scholarly research.

I further authorize Ryerson University to reproduce this thesis by photocopying or by other means, in total or in part, at the request of other institutions or individuals for the purpose of scholarly research.

I understand that my thesis may be made electronically available to the public 


\title{
Cancer Worry Interference and Health Service Utilization in Women with Lynch Syndrome: The Role of Trusting One's Physician
}

\author{
Lindsey Torbit \\ Master of Arts \\ Psychology \\ Ryerson University
}

2013

\begin{abstract}
Lynch syndrome (LS) is a genetic predisposition to adult-onset of multiple cancers. Some high risk women report significant cancer-specific distress (Ritvo et al., 1999) and highly anxious high risk women may utilize more medical services than those who are less anxious (e.g., Bish et al., 2002). Trust in one's physician has been found to be associated with less anxiety and distress in patients and a reduction in medical visits. The current study examined the association between intolerance of uncertainty and prior cancer diagnosis with cancer-specific worry interference and medical utilization in women with LS ( $\mathrm{N}=128)$ via self-report measures. Additionally, trust in physician was examined as a moderator. Findings indicated higher intolerance of uncertainty was associated with more worry interference, and having more trust in one’s physician moderated this relationship. Having a greater number of prior cancer diagnoses was also associated with both outcomes, but trust in physician did not moderate these relationships. The implications for potential intervention are discussed.
\end{abstract}




\section{Acknowledgments}

First and foremost, I would like to thank my supervisor Dr. Tae Hart, who has mentored and guided me to become a more thoughtful and conscientious researcher. I would also like to thank my thesis committee members, Dr. Trevor Hart, and Dr. Stephanie Cassin, for their insightful feedback.

Thank you to all of the members of the Psychosocial Medicine Laboratory who all played a role in making this thesis possible. A special thanks to Joe and Aliza for your help with data collection and preparation, and to Jenna, Dani and Cassie for your guidance and support.

I would like to thank my sister, Meghan, for her love and support throughout my academic journey and life. I am truly thankful to have you as my sister and best friend. 
To my husband, Rob, for his ongoing support, unconditional love and endless encouragement. You inspire me everyday. 
Introduction.............................................................. 1

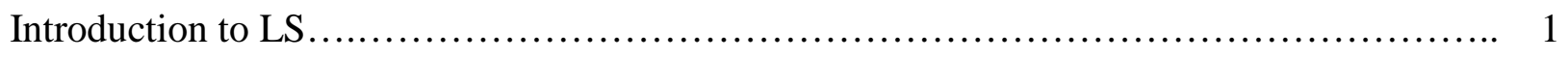

Distress in LS........................................................ 2

Guidance Conceptual Model............................................. 3

Cancer-Specific Worry Interference: A Specific Form of Distress.................. 5

Intolerance of Uncertainty as a Predictor of Cancer-Related Distress in LS. ......... 7

Prior Cancer Diagnosis as a Predictor of Cancer-Related Distress in LS............ 8

Predictors of Increased Medical Service Utilization in LS ........................ 10

Prior cancer diagnosis as a predictor of medical utilization................ 10

Psychological predictors of medical utilization............................... 11

The Beneficial Role of Trust in One's Physician............................. 12

Trust in one's physician and distress................................. 12

Trust in one's physician and medical service utilization.................... 14

Summary of Current Research........................................... 14

Study Aims and Hypotheses............................................. 15

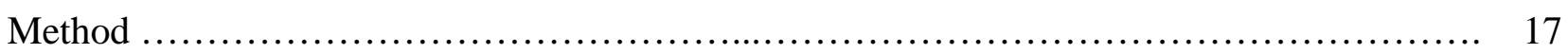

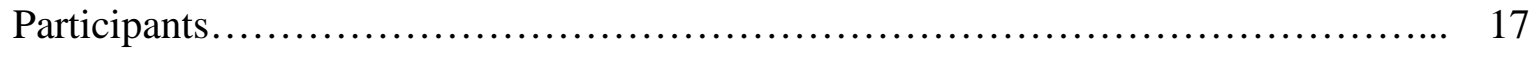

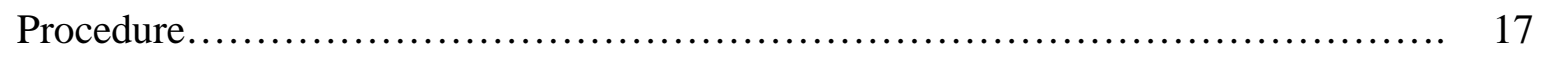

Measures............................................................. 18

Worry Interference Scale....................................... 18

Medical Utilization Measure............................................ 19

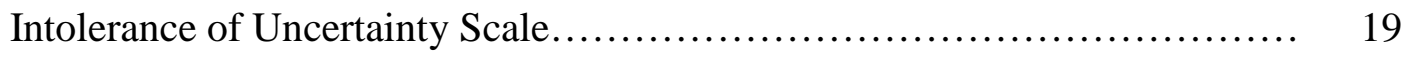

Number of Cancer Diagnoses...................................... 19

Trust in Physician Scale.......................................... 20 
Data Analysis................................................................... 20

Power Analyses............................................................. 21

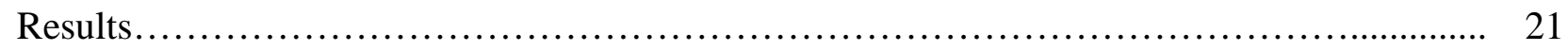

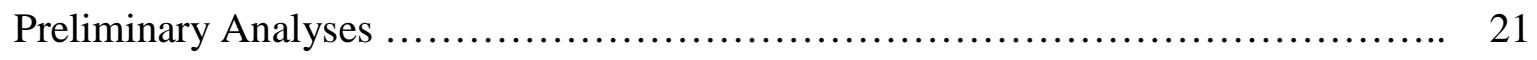

Participant Demographics...................................................... 22

Descriptive Information on Key Variables............................................... 23

Medical Service Utilization................................................ 23

Worry Interference....................................................... 23

Intolerance of Uncertainty............................................ 24

Number of Prior Cancer Diagnoses........................................ 24

Trust in Physician...................................................... 24

Tests of Hypotheses............................................................. 24

Aim One: Hypothesis 1a.............................................. 25

Aim One: Hypothesis 1 b................................................. 25

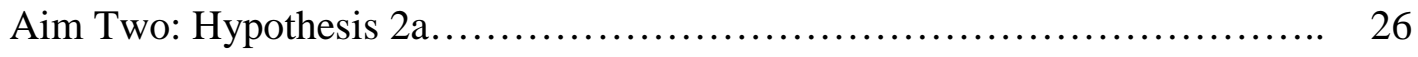

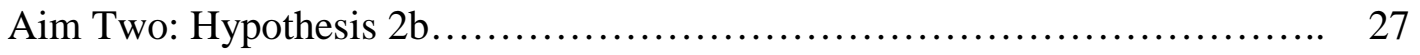

Aim Three: Hypothesis 3a............................................... 28

Aim Three: Hypothesis 3b.............................................. 29

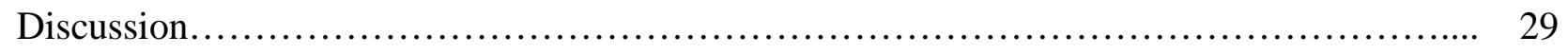

Summary of Findings.......................................................... 29

Predictors of Cancer-Specific Worry Interference............................... 29

Intolerance of Uncertainty as a Predictor of Cancer-Specific Worry 29

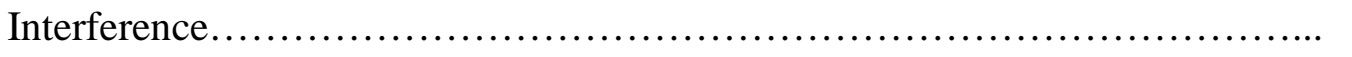

Prior Cancer Diagnosis as a Predictor of Cancer-Specific Worry Interference. 
Predictors of Medical Utilization........................................... 32

Intolerance of Uncertainty as a Predictor of Medical Utilization............. 32

Prior Cancer Diagnosis as a Predictor of Medical Utilization................. 33

Moderating Effect of Trust in Physician...................................... 33

The role of physician trust in the association between intolerance of uncertainty and the outcomes (cancer-specific worry interference and medical

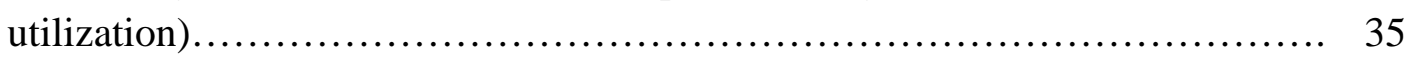

The role of physician trust in the association between prior cancer diagnosis and the outcomes (cancer-specific worry interference and medical

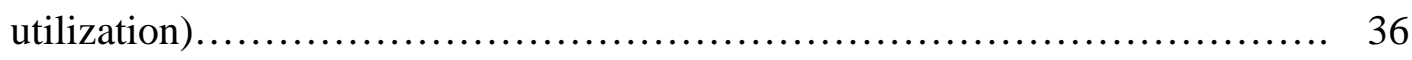

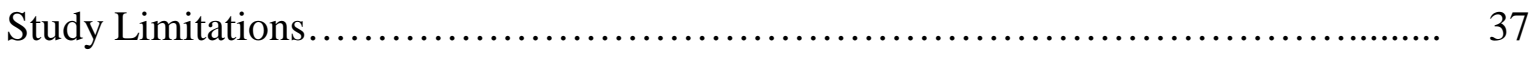

Future Directions and Theoretical Considerations.............................. 39

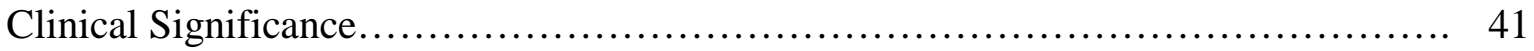

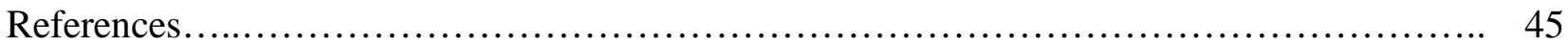

Appendix A................................................................. 80

Appendix B............................................................... 81

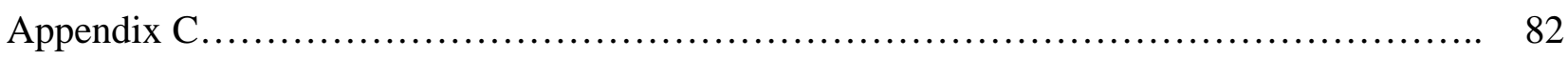

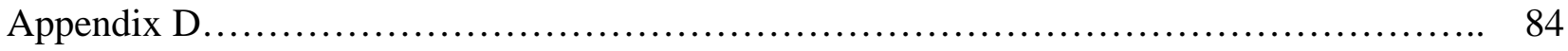

Appendix E................................................................. 85 
Table 1: Sample demographics...................................................... 60

Table 2: Cancer diagnoses................................................... 62

Table 3: Regression results for association of intolerance of uncertainty and the outcome

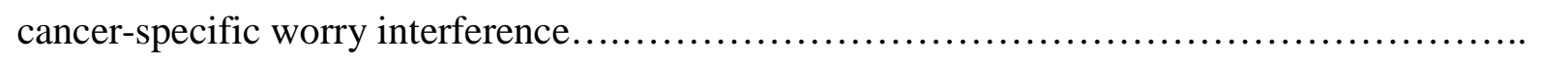

Table 4: Regression results for association of intolerance of uncertainty with outcome

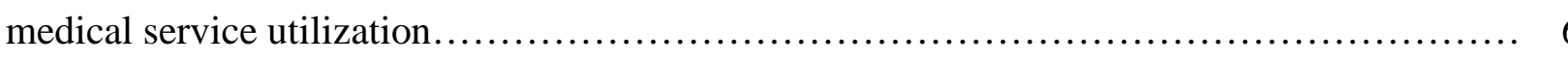

Table 5: Regression results for association of number of times diagnosed with cancer with

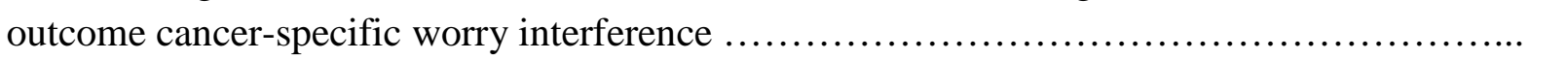

Table 6: Regression Results for association of number of times diagnosed with cancer with outcome medical service utilization................................................

Table 7: Moderation analyses predicting worry interference by intolerance of uncertainty and trust in physician, controlled for age, education, first degree relatives diagnosed with LS

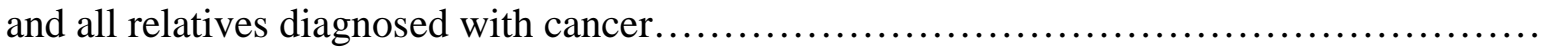

Table 8: Moderation analyses predicting medical utilization by intolerance of uncertainty and trust in physician, controlled for age, education, first degree relatives diagnosed with LS and

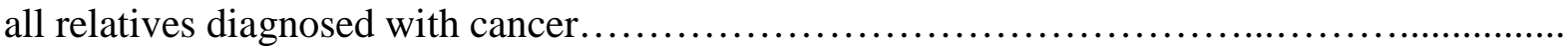

Table 9: Moderation analyses predicting worry interference by prior cancer diagnoses and trust in physician, controlled for age, education, first degree relatives diagnosed with LS and

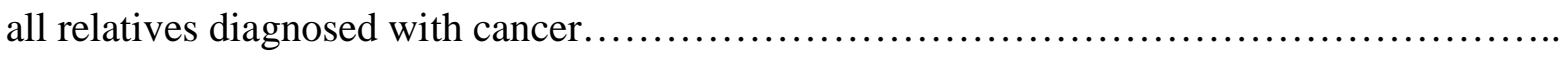

Table 10: Moderation analyses predicting medical utilization by prior cancer diagnoses and trust in physician, controlled for age, education, first degree relatives diagnosed with LS and all relatives diagnosed with cancer. 


\section{Lists of Figures}

Figure 1: Aim 1: Hypothesized relationship of intolerance of uncertainty with worry interference and medical service utilization....

Figure 2: Aim 2: Hypothesized relationship of number of prior cancer diagnoses with worry interference and medical service utilization...

Figure 3: Aim 3: Hypothesized moderation of relationship between predictors (intolerance of uncertainty and prior cancer diagnosis) and outcomes (worry interference and medical service utilization) by trust in physician...

Figure 4: Trust in physician moderating the relation between intolerance of uncertainty and worry interference. 
Cancer Worry Interference and Health Service Utilization in Women with Lynch Syndrome: The Role of Trusting One's Physician

Lynch syndrome (LS), also known as hereditary nonpolyposis colorectal cancer (HNPCC), is a genetic mutation, which predisposes an individual to an increased risk of early onset of multiple cancers. The most common cancer associated with LS is colorectal cancer, but for women, gynecological malignancies such as endometrial and ovarian cancer are also highly prevalent (Watson \& Riley, 2005). Research has indicated that a significant minority of individuals experience psychological distress when they are identified as being a carrier of this mutation (Broadstock, Michie, \& Mateau, 2000). However, prior research has largely ignored the psychological impact of gynecological cancer risk for women with LS. The present study seeks to examine predictors of psychological distress (i.e., cancer worry interference) and behavioral manifestations of distress (i.e., elevated medical utilization) in women with LS, guided by a cognitive behavioral framework of people worrying about their health.

\section{An Introduction to LS}

LS is a genetic condition characterized by a predisposition to adult-onset cancers. People diagnosed with LS are at higher risk of cancers of the colon, endometrial, small intestine, ovary, hepatobiliary, kidney, ureter, and brain compared to individuals without LS (Aarnio et al., 1999; Lynch et al., 2003; Watson \& Riley, 2005). The mutations associated with LS are four mismatch repair genes (MLH1, MSH2, MSH6, and PMS2). A mutation in one of these genes predisposes the carrier to a lifetime risk of almost 90\% for developing one of these cancers (Hampel et al., 2008). Specifically, LS is the most common form of hereditary colorectal cancer (CRC) and accounts for 3\% of all types of incident CRC (Hampel et al., 2008). LS also accounts for approximately 2.3\% of all incident endometrial cancers (Lindor et al., 2006). Importantly, it is 
estimated for mutation carriers that the cumulative risk of developing any LS-related cancers by age 70, in the absence of cancer screening, is between $47 \%$ and $85 \%$ (Jenkins et al., 2006).

The lifetime risk for developing colorectal cancer (CRC) for LS carriers is 80\% (Aarnio et al., 1999), compared to the lifetime risk of $6 \%$ in the general population. Traditionally, LS has been perceived as a CRC dominated syndrome. As a result, the LS literature has largely focused on CRC, to the neglect of the other cancers. However, women with LS have a lifetime risk of endometrial carcinoma that meets or exceeds their colorectal cancer risk and is also dramatically elevated compared to the general population: $40-60 \%$ compared to $3 \%$ in the general population (Lindor et al., 2006). Women with LS are therefore additionally faced with a significantly heightened risk for gynecological cancers. Not surprisingly, living with LS and the associated threat of cancer can lead to negative psychological reactions, such as uncertainty, distress, and worry, which are the foci of the current study.

\section{Distress in LS}

The majority of the psychosocial literature on LS has focused on the impact of genetic testing. Predictive genetic testing can identify whether an individual carries a gene mutation (i.e., mutation carrier or non-carrier), which increases one's risk for developing a specific disease or disorder (Lerman \& Shields, 2004). Cancer-related genetic testing may be particularly stressful because positive results indicate substantial lifetime risks (Ritvo et al., 1999). To date, this literature has examined psychological distress surrounding the genetic testing procedure and factors related to screening behavior.

Those data show some individuals do exhibit increased distress immediately after disclosure of a positive genetic test result (Claes et al., 2003; Hoogerbrugge et al., 2008; von Oostrom et al., 2007). Individuals who appear to be at risk for increased distress tend to be 
younger, less educated, have had a prior diagnosis of cancer (Rimes et al., 2006), and have an increased number of family members affected by cancer (Consedine, Magai, Krivoshekova, Ryzewicz, \& Neuget, 2004) compared to those with lower distress. Although this information is useful in helping to identify those who are potentially vulnerable to increased distress in the short term following a positive result, the literature on the psychological adaptation in living with LS is lacking. Aside from these potentially predisposing demographic variables, research into the psychosocial factors that predict increased levels of distress in this population is needed for a more comprehensive understanding of the experience of this population.

Given this dearth of information, examining the literature on other hereditary forms of cancer can help to inform our understanding of psychological adjustment in LS. Specifically, the data from the hereditary breast and ovarian cancer literature (i.e., BRCA 1/2), in which female carriers of the BRCA genetic mutation have a lifetime risk of breast cancer that exceeds $80 \%$ and of ovarian cancer up to 60\% (Lancaster, Carney, \& Futreal, 1997), can help identify factors important to the psychological adjustment of living with a genetic cancer mutation. Therefore, the empirical data on adjustment to BRCA can inform our understanding of the experience of women with LS.

\section{Guiding Conceptual Model}

Although health worries are common in cancer patients or in those with hereditary cancer conditions, surprisingly little theoretical or conceptual work has focused on the determinants of health worry in these individuals. Therefore, examining more general models of people worrying about their health, such as the cognitive-behavioral model of hypochondriasis, can serve as a conceptual framework to enhance understanding of cancer-related worry in the LS population. 
The foundational feature of hypochondriasis is a fixation on having a serious medical illness that is based on misinterpretations of benign bodily sensations. Due to prominent fears and ideas about life-threatening disease, hypochondriacal people have high levels of healthrelated anxiety (Nakao, Shinozaki, Ahern, \& Barski, 2011). In Warwick and Salkoviskis’ (1990) cognitive behavioral model of hypochondriasis and health anxiety, excessive worry is conceptualized to arise from dysfunctional beliefs about sickness, health, and healthcare.

The cornerstone of this model—-the proposition that health-anxious individuals hold dysfunctional medical and illness-related beliefs—has received strong empirical support. For example, when presented with a list of somatic complaints and asked to classify them as healthy or unhealthy based on the list, patients diagnosed with hypochondriasis have been found to classify a person with common somatic complaints as "not healthy" compared to a control group of medical patients (Barsky, Coeytaux, Sarnie, \& Cleary, 1993). Similarly, a study wherein college students who were presented with descriptions of bodily sensations and asked to indicate thoughts that accompanied each description revealed that individuals high in hypochondriasis were more likely to report thoughts related to catastrophic illness compared to the participants low in hypochondriasis (Hitchcock \& Matthews, 1992). Elevated health anxiety, which is consistent with hypochondriasis, is also often observed among individuals with medical conditions such as chronic pain (Tang, Wright, \& Salkovskis, 2007) and multiple sclerosis (Kehler \& Hadjistavropoulos, 2009), compared to non-medical groups (Alberts, Sharpe, Kehler, \& Hadjistavropoulos, 2011).

While not suggesting that hypochondriasis and LS are the same illnesses, drawing from this model helps to explain psychological factors related to health worries. Specifically, according to this model, dysfunctional illness beliefs, including intolerance of uncertainty, can be 
triggered by a critical incident, such as the genetic testing procedure or receiving positive mutation results, and can lead to catastrophic cognitions about illness and an increase in the number of safety-seeking health behaviors (Marcus, 1999).

Health anxiety and hypochondriasis are similar constructs and there is observable overlap with the cognitive model of health anxiety and the cognitive-behavioral model of hypochondriasis. Both models state that dysfunctional illness beliefs are triggered by a critical incident and that these triggered beliefs lead to anxiety, hypervigilance about bodily symptoms/sensations, and reassurance/safety seeking behaviors. However, the one major difference is that the hypochondriasis model specifically calls medical burden into account. Given the actual medical burden of patients with LS, the hypochondriasis model was chosen as the guiding model in the current study.

\section{Cancer-Specific Worry Interference: A Specific Form of Distress}

Overall, research findings from both the LS and BRCA 1/2 populations suggest that undergoing predictive genetic testing does not lead to negative psychological effects for the individual being tested (Broadstock et al., 2000). However, although the majority of women undergoing testing experience average levels of depression and anxiety, there remain a significant proportion of individuals with LS and BRCA 1/2 who exhibit significant distress, at least during the time of their initial assessment and follow-up. For example, Ritvo and colleagues (1999) found that in a sample of 157 women undergoing familial genetic assessment, 33\% had depression scores in the clinical range on the Center for Epidemiologic Studies Depression Scale (CES-D). Further, out of 65 of these participants, 38\% continued to have clinical depression scores at their 6- or 12-month follow-up appointment. Additionally, in a recent review of adaptation to living with a genetic condition or risk for a genetic condition, 
Biesecker and Erby (2008) reported that about one third of individuals who received positive results for genetic testing failed to adjust well.

Because global levels of distress have not consistently been shown to be high for the average woman with a BRCA mutation, researchers have narrowed their focus to the examination of 'cancer-specific' distress and cancer-specific worry (e.g., Trask et al., 2001). Indeed, one recent systematic review concluded that women with a positive BRCA mutation results experienced increases in cancer-related distress after testing, but their levels of global depression and anxiety remained the same from pre-testing (Butow, Lobb, Meiser, Barratt, \& Tucker, 2003). Furthermore, this cancer-specific worry reported by women at increased risk for breast cancer can manifest as intrusive thoughts (Baider \& De-Nour, 1997; Zakowski et al., 1997; Epping-Jordan et al., 1999) and can disrupt functioning in a variety of areas (Wellisch, Gritz, Schain, Wang, \& Siau, 1991, 1992). Indeed, Trask and colleagues (2001) examined women at high risk of developing breast or ovarian cancer, to specifically assess their perceptions of the interference that cancer-specific worries created in their daily functioning. Results from this study showed that approximately two-thirds of a high-risk breast cancer clinic sample perceived worries about breast cancer as interfering with their functioning across a variety of life domains, such as sleep, work, concentration, relationships, having fun, and feeling sexually attractive (Trask et al., 2001). Further, those with higher worry interference reported higher levels of anxiety and confusion, diminished mental health, and difficulty in role fulfillment such as in performing their usual roles in and outside the home. In addition, analyses revealed that experiencing the worry as interfering, rather than the frequency of the worry that accounted for the variance on these scales (Trask et al., 2001). 
In women with a personal or family history of breast cancer, more cancer worry has been associated with increased medical service utilization such as screening, higher cancer risk perception, and lower levels of quality of life. However, the findings are not always consistent across studies. One study found that in a sample of 282 women with a family history of breast cancer, high levels of cancer-specific distress were reported both pre- and post-genetic consultation as well as at a 12 month follow-up (Watson et al., 1999). Specifically, $28 \%$ of this sample reported worrying about breast cancer 'frequently or constantly' and $18 \%$ of participants reported that their level of worry about breast cancer was a 'severe or definite problem' (Watson et al., 1999). However, others have found low to moderate levels of cancer worry in high risk individuals, revealing inconsistency with regards to whether high-risk samples have more cancer worry than the general population (Anderson \& Newman, 2003). Clearly, our understanding of cancer-related worry as a specific form of psychological distress for those with LS is limited, as is our knowledge of psychological predictors of worry interference in this population.

\section{Intolerance of Uncertainty as a Predictor of Cancer-Related Distress in LS}

In the general population, situational uncertainty about a health threat can lead to increased anxiety, especially when that threat remains ambiguous over time (Maissi et al., 2004). Therefore, one possible explanation for the equivocal results regarding cancer worry is that the amount of anxiety and distress experienced may be contingent on the degree of perceived uncertainty in the health threat (Rosen et al., 2010). Another potential explanation is that there may be individual differences in how one responds to general uncertainty, which have not been assessed in past research. One such individual difference in responses to ambiguity is referred to as intolerance of uncertainty (O’Neill et al., 2006). Whereas situational uncertainty is defined by the perceived characteristics of a situation, intolerance of uncertainty, in contrast, refers to a trait of the individual: "A predisposition to react negatively to an uncertain event or situation, 
independent of its probability of occurrence and its associated consequences” (Ladouceur, Gosselin, \& Dugas, 2000, p.934).

In the anxiety literature, uncertain situations have been demonstrated to induce and perpetuate greater psychological distress in individuals who are higher in intolerance of uncertainty (Dugas, Gosselin, \& Ladouceur, 2001; Greco \& Roger, 2003; Ladouceur et al., 2000). Further, intolerance of uncertainty has been shown to be positively correlated with negative mood states including worry, anxiety and depression (Freeston, Rhéaume, Letarte, Dugas, \& Ladouceur, 1994). Of particular significance, intolerance of uncertainty has been shown to be strongly associated with worry (Buhr \& Dugas, 2002; Dugas, Freeston, \& Ladouceur, 1997), even after controlling for shared variance with measures of global anxiety and depression (Dugas et al., 1997; Freeston et al., 1994).

Uncertainty is pervasive in the healthcare setting (Eton, Lepore, \& Helgeson, 2005;

Mishel et al., 2005). Given the inherent uncertainty associated with being a mutation carrier for hereditary cancer, it is likely that individuals high in intolerance of uncertainty within this population are at a heightened risk of experiencing increased distress (O’Neill et al., 2006). Indeed, reduction of uncertainty is an important goal of genetic counseling for women from families with a strong history of breast and/or ovarian cancer (Vos et al., 2012). Further, the BRCA1/2 literature has shown that higher cancer-related distress is associated with greater intolerance of uncertainty (O’Neill et al., 2006); however, this has yet to be examined among those with LS.

\section{Prior Cancer Diagnosis as a Predictor of Cancer-Related Distress in LS}

Women who have already been diagnosed with cancer (“affected" women) make up a significant proportion of those who seek testing for a genetic mutation (Bish et al., 2002). There is emerging evidence that among those at high risk, individuals with a prior diagnosis of cancer 
may be especially vulnerable to psychological distress compared to mutation carriers without a cancer history ("unaffected” mutation carriers). Indeed, research has begun to explore factors associated with this potential increased vulnerability for distress and suggests that unlike unaffected individuals, cancer patients receiving genetic testing may already be coping with an unusually young age of onset, multiple primary cancers, and/or poor health resulting from disease and/or treatment (Engel et al., 2003; Kerr, Engel, Schlesinger-Raab, Sauer, \& Holzel, 2003; Schofield et al., 2003), which may predispose them to worse psychological outcomes. In accordance, there is a growing literature across diverse high-risk cancer populations showing that distress differs for affected versus unaffected individuals. In a study of 121 affected and unaffected adults with a family specific mutation in the CDKN2A melanoma susceptibility gene, having a personal history of melanoma was significantly associated with melanoma-specific distress (Kasparian, Meiser, Butow, Simpson, \& Mann, 2008). Research has also revealed that individuals with a cancer history tend to experience more psychological distress even prior to receiving genetic test results than do non-affected individuals. For example, Bish and colleagues (2002) assessed distress and worry in women before they attended a genetic counseling clinic for BRCA 1/2 testing and found that affected women were more worried about developing ovarian cancer than unaffected women. Other studies have found consistent results, demonstrating that women with cancer (vs. unaffected) are significantly more distressed at baseline and 6 weeks following genetic testing (Reichelt, Heimdal, Moller, \& Dahl, 2004), and report more breast cancer worry throughout the testing process, independent of mutation status. Moreover, receiving positive test results appear to have a greater impact on anxiety and cancer-related distress in affected women than it does in mutation positive nonaffected women (van Roosmalen et al., 2004). 
These results from the BRCA1/2 literature have also been demonstrated in a prospective study of patients with suspected LS, wherein Keller and colleagues (2008) examined 139 affected individuals and 233 unaffected family members. Even before testing, affected individuals reported significantly more severe and intrusive distress specific to the hereditary condition and this difference was maintained 8 weeks after the counseling session. Furthermore, affected individuals reported that their worry about their family member's cancer risk impaired daily functioning (Keller et al., 2008). Although the current study is not focused on genetic testing, collectively, these studies reveal that women with a cancer history may be a particularly vulnerable subgroup of high risk women.

\section{Predictors of Increased Medical Service Utilization in LS}

Prior cancer diagnosis as a predictor of medical utilization. Not surprisingly, individuals with a cancer history have been shown to use more health care services than those without a prior cancer diagnosis (Hewitt, Rowland, \& Yancik, 2003; Stafford \& Cyr, 1997) and have also been found to seek out more additional complementary and alternative medicine compared to the general population (Lafferty et al., 2004). Cancer registry data from the Netherlands has shown that health care utilization rates one year post-diagnosis were significantly higher among treated breast cancer patients compared to age-matched healthy controls (Roorda, Berendsen, Groenhof, van der Meer, \& de Bock, 2012). Other research has demonstrated that a prior cancer diagnosis is associated with the largest annual Medicare reimbursements amongst the elderly, as well as higher rates of physician visitation and more days of inpatient hospitalization compared with patients who did not have cancer (Stafford \& Cyr, 1997). In addition, a National Health Interview Study (NHIS)-based study conducted by Hewitt and colleagues (2003) found that cancer survivors, compared with their counterparts who 
had no history of malignancy, were more likely to visit physician specialists and therapists but similarly likely to visit general practitioners (Hewitt et al., 2003). Although it is very possible that individuals with a cancer history legitimately require more medical services for management and possible increased comorbities, there may also be other patient characteristics involved that are potentially amenable to intervention, which might ultimately reduce costs to the health care system. For example, beyond physical symptoms, increased distress or cancer-specific worry may prompt certain individuals to seek more health care services.

Psychological predictors of medical utilization. Women with a family history of breast cancer and who experience high breast cancer-specific worry have been shown to seek more medical services and attention than high-risk women who are less worried. In Watson and colleagues' (1999) study, 34\% of the sample reported that they sought the referral to the genetic clinic themselves because they were anxious, and further, this anxiety was not relieved after a session of genetic counseling. Watson and colleagues (1999) referred to these women as the 'worried well' and suggested that they constitute a subset of people saturating the healthcare system. Although many of these women were recommended by the clinic to be monitored by their general practitioner, likely due to increased worry they made their way into specialist genetic services (Watson et al., 1999). This is in line with the cognitive-behavioral model of hypochondriasis that suggests that anxiety and uncertainty can lead to safety-seeking health behaviors. Even though such use of medical services is not necessarily inappropriate, it is possible that such individuals might be managed in a less expensive manner.

Although the relationship between intolerance of uncertainty and medical service utilization has not directly been assessed, in a study of undergraduate students examining whether individual differences in intolerance of uncertainty affect people's health behaviours, 
Rosen, Knauper and Sammut (2007) found that experimentally inducing high intolerance of uncertainty led to greater intentions to seek information about a health threat, specifically human papilloma virus (e.g., perform an Internet search, get tested for an sexually transmitted infection, and increased requests for information). These findings suggest that high intolerance of uncertainty induces people to increase their monitoring when faced with a health threat (Rosen et al., 2007).

Importantly, research has shown that individuals with generalized anxiety disorder (GAD) seek more medical services than those without GAD. This link is of particular relevance as intolerance of uncertainty is considered to be a hallmark feature of GAD, wherein core features of this disorder involve efforts to reduce the anxiety associated with uncertain outcomes (Gentes \& Ruscio, 2011). A recent review by Bereza and colleagues (2009) has revealed that patients with GAD are high utilizers of primary care services, specifically stating that they are at least four times more likely to visit a physician five or more times a year, compared with patients who had not been diagnosed with GAD (Belanger, Ladouceur, \& Morin, 2005). Furthermore, patients with GAD visited their physicians more frequently than those who did not have the disorder (Belanger et al., 2005). Finally, two studies revealed that primary care patients with GAD incurred higher medical costs that patients without GAD (Marciniak et al., 2005; Olfson \& Gameroff, 2007). Therefore, people who worry excessively about everyday issues and report high intolerance of uncertainty, as in GAD, have been shown to seek more medical services than individuals without GAD. Although the link between intolerance of uncertainty and medical service utilization has not been directly investigated, it seems to logically follow from the GAD and health monitoring literature that one's level of intolerance of uncertainty may play a role in their health-care seeking behavior. 


\section{The Beneficial Role of Trust in One's Physician in Worry and Medical Utilization in LS}

Trust in one's physician and distress. Trust is a defining element in any interpersonal relationship, but is particularly central to the patient-physician relationship. A growing body of research has shown that positive appraisals of one's physician appear to have a significant impact on improving patients' satisfaction with care, physical and mental health outcomes as well as reductions in medical care costs (Buller \& Buller, 1987; Chewning \& Sleath, 1996; Stewart, 1995). In cases where the illness is more serious or life-threatening, such as cancer, the physician's role assumes an even greater significance in ameliorating patient distress and anxiety levels (Takayama et al., 2001). Feeling confident in one’s physician and their delivery of care have previously been linked to increased cancer patient satisfaction. In addition, patients' psychological symptoms, such as depression and anxiety, seem to also be influenced by these patient-physician interactions (Brown, Boles, Mullooly, \& Levinson, 1999).

One possible explanation for the impact of having trust in one's physician and more positive health outcomes is that viewing one's physician as a credible source of information (e.g., informational support) reduces feelings of uncertainty around one's health (Padilla, Mishel, \& Grant, 1992). As such, having a positive appraisal of their physician may help protect individuals with LS from the negative outcomes and uncertainty associated with the knowledge of having a heightened vulnerability to many cancers. Indeed, several studies have reported a significant positive relationship between support from one's healthcare provider and breast cancer patients' health outcomes, including both higher levels of health-related quality of life (e.g., Bloom, Stewart, Johnston, Banks, \& Fobair, 2001) and increased immune function (e.g., Lekander, Furst, Rotstein, Blomgren, \& Fredrikson, 1996). 
In addition to relying on them for information, decision-making and a treatment plan, cancer patients often seek reassurance from their physicians (Rose, 1990; Takayama, Yamazaki, \& Katsumata, 2001). Several studies suggest that a good interpersonal relationship with their physician, characterized by caring, compassion, respect, and trust can significantly help cancer patients adjust better to their illness (e.g., Bakker, Fitch, Gray, Reed, \& Bennett, 2001; McWilliam, Brown, \& Stewart, 2000). Given the uncertainties associated with the disease and its treatment, cancer patients often require significant amount of reassurance about the normalcy and legitimacy of their reactions and concerns (Rose, 1990). Therefore, it appears that patients look towards their healthcare providers to meet several of their information and support needs, which if met, are likely to reduce the disruption in their QOL (Rose, 1990; Schain, 1990).

Trust in one's physician and medical service utilization. Consistent with the cognitivebehavioral model of hypochondriasis, medical utilization for those high in intolerance of uncertainty may constitute a safety-seeking or reassurance distress-related behavior. One likely influence on medical utilization as a safety-seeking behavior is one’s trust in their physician. Research into long-term management of cancer survivors has demonstrated that most patients prefer to be cared for by specialists due to concerns about the amount of knowledge and skills, and time involved for general practitioners to provide adequate follow up care (de Bock et al., 2004; Renton, Twelves, \& Yuille, 2002; van Hezewijk et al., 2011). As such, this may be a reflection of trust in one's physician, and improvement in this area may facilitate effective resource allocation between primary care and hospital care in the future by increasing the willingness of patients to transfer their cancer follow-up to the primary care setting (van Hezewijk et al., 2011). 


\section{Summary of Current Research}

Extant research has demonstrated that certain high risk individuals experience significantly elevated cancer-specific worry that interferes with their daily lives (Trask et al., 2001). However, there is a scarcity of research on the factors that contribute to this heightened distress. A growing body of research has revealed that individuals who have already been diagnosed with cancer appear to experience more cancer-specific worry relative to mutation carriers without a cancer history (Keller et al., 2008). Additionally, the BRCA $1 / 2$ literature has demonstrated that higher cancer-related distress is associated with greater intolerance of uncertainty (O’Neill et al., 2006); however, this association has yet to be examined in LS. Furthermore, in addition to potentially being factors associated with increased cancer-specific distress, having a history of cancer and heightened intolerance of uncertainty may also predict more medical service utilization. Beyond physical complaints, there is evidence that heightened anxiety predicts more medical service utilization among high risk women (Watson et al., 1999) and among individuals with GAD (Marciniak et al., 2005; Olfson and Gameroff, 2007). Research into the role of the physician suggests that having more trust in one's physician can be particularly beneficial for individuals who are faced with life-threatening illnesses, such as cancer (Takayama et al., 2001). Specifically, having more trust in one’s physician has been shown to be associated with less anxiety and distress (Brown et al., 1999) and may help reduce the unnecessary burden on specialists and overall cost of managing high risk patients (van Hezewijk et al., 2011).

Following from the hypochondriasis framework, the current study will investigate intolerance of uncertainty and having a prior cancer diagnosis as predictors of cancer-specific worry interference and medical service utilization (i.e., a potential safety-seeking health 
behavior). Further, the role of trust in one's physician in moderating these relationships will be examined.

\section{Study Aims and Hypotheses}

Aim 1: To examine the relationship of intolerance of uncertainty with the outcomes of worry interference and medical service utilization.

1a. It is hypothesized there will be a significant relationship between greater intolerance of uncertainty and more worry interference (See Figure 1).

1b. It is hypothesized there will be a significant relationship between more intolerance of uncertainty and increased medical service utilization (See Figure 1).

\section{See Figure 1}

Aim 2: To examine the relationship of prior cancer diagnosis with the outcomes of worry interference and medical service utilization.

2a. It is hypothesized there will be a significant relationship between higher number of prior cancer diagnoses and greater worry interference (See Figure 2).

2b. It is hypothesized there will be a significant relationship between higher number of prior cancer diagnoses and more medical service utilization (See Figure 2).

See Figure 2

Aim 3: To examine trust in physician as a moderator of the relationship between the predictors (intolerance of uncertainty and number of prior cancer diagnoses) and the outcomes of worry interference and medical utilization. 
3a. It is hypothesized that people who have more trust in their physician will be buffered against the effects of intolerance of uncertainty on the outcomes of cancer worry and medical service utilization compared to those have less positive views about their physician (See Figure 3).

3b. It is hypothesized that people who have more trust in their physician will also be buffered against the effects of number of prior cancer diagnoses on the main outcomes (worry interference, medical service utilization) compared to those that have less trust in their physician (See Figure 3).

See Figure 3

\section{Method}

\section{Participants}

Participants were women who have already provided consent to participate in the Familial Gastrointestinal Cancer Registry (FGICR), which is housed at the Zane Cohen Centre for Digestive Diseases at Mount Sinai Hospital in Toronto, Canada. The FGICR, established in 1980, is a database comprised of patients and families at high risk of hereditary gastrointestinal cancers. The purpose of the FGICR is to study and understand a variety of variables (e.g., genetic mutations, family history) related to inherited gastrointestinal cancer syndromes, such as LS. As members of the FGICR, all participants have provided permission to be contacted for future research studies.

Participants for the current study were recruited as part of a larger research project that is focused on gynecological cancer risk management specifically in women with LS. Participants were eligible for the study if they were female, over 18 years of age, have a confirmed diagnosis 
of LS, and are a participant in the FGICR. Participants were excluded if they were male and/or under 18 years of age.

\section{Procedure}

All eligible FGICR patients with a confirmed diagnosis of LS $(N=235)$ were mailed an informational letter, consent form, questionnaire packet, and stamped return envelope. Of this number, 23 were not able to be contacted because they did not have a listed phone number or their phone number was out of service, 6 were returned due to an incorrect address, and 2 were unable to complete the questionnaire due to language difficulties, which left 204 eligible patients. Consent for the current study was written and obtained at the time that the questionnaire packet was received. If a potential participant had questions, email contact information and a toll-free number were provided. One hundred and twenty eight patients returned questionnaires (67.2\% response rate). Eligible patients who did not send back questionnaires ( $n=76$ ) were contacted by research personnel to inquire about the status of the questionnaire. Research burn-out and current medical struggles were reported as the primary reasons for non-completion.

A one-time self-report questionnaire survey was completed by participants. The time required for completion was approximately 60 minutes. After completion, the participant mailed back the questionnaire to the Zane Cohen Centre for Digestive Diseases in a stamped, addressed return envelope. Those who returned completed questionnaires received a \$20 gift card as a thank you for their time.

\section{Measures}

\section{Primary outcome measures.}

Worry Interference Scale. The Worry Interference Scale (Trask et al., 2001) is a reliable and valid measure, which assesses the degree to which thoughts about breast cancer are 
perceived as interfering with one’s daily functioning. For the purpose of the present study, the scale was adapted to assess the interference caused by LS as opposed to breast cancer (e.g., “Worries about Lynch syndrome have affected my ability to meet the needs of my family”; refer to Appendix A). The 11-items included in the original scale validation paper were used. All items were assessed on a 5-point multiple-choice scale ranging from “not at all” to “a lot.” An example of an item on the questionnaire is "Lynch syndrome concerns have affected my ability to concentrate”. The validated scale demonstrated good internal consistency in the current study (Cronbach’s $\alpha=.79$ ).

Medical Utilization Measure. Medical utilization was assessed via patient self-report, with items created for a prior study of cancer patients (Stanton et al., 2002; refer to Appendix B). No data have been published regarding the validity and reliability of this measure. Participants were asked to indicate how many times over the past six months they made visits to various health professionals. Participants were provided with a list of seven categories of health professionals and were also provided space to add in an unlisted medical specialist, if needed. To produce a total number of medical visits for each participant, we created a variable that counted across each of the seven categories of visits.

\section{Predictor measures.}

Intolerance of Uncertainty Scale (short version). The original Intolerance of Uncertainty Scale (IUS) is a 27-item validated measure of reactions to ambiguous situations, uncertainty, and future events (Freeston et al., 1994). The current study used the shortened 12item measure (refer to Appendix C), which has demonstrated good internal consistency (Cronbach's $\alpha=.91$ ). The internal consistency was also comparably high in our sample (Cronbach's $\alpha=.87$ ). The 12-item version also has been shown to correlate strongly with the 
original IUS as well as other measures of anxiety and worry (Carleton, Norton, \& Asmundson, 2007). Each item is rated on a Likert scale ranging from 1 (not at all characteristic of me) to 5 (entirely characteristic of me). Examples of items include; "I always want to know what the future has in store for me,” and “When I am uncertain, I can’t function very well”.

Number of cancer diagnoses. Information relating to the number of cancer diagnoses was obtained through self-report (refer to Appendix D). Participants were asked to indicate whether they had ever been diagnosed with cancer, and to list the type(s) of cancer they were diagnosed with and their age at diagnosis.

\section{Moderator Measure}

The Trust in Physician Scale. The Trust in Physician Scale is an 11-item self-report measure that assesses patient trust in physician in the domains of dependability, confidence, and confidentiality of information (Anderson \& Dedrick, 1990; refer to Appendix E). All items are fashioned in a 5-point Likert format, with a combination of positively and negatively worded questions. For example, positively worded questions are "My doctor is usually considerate of my needs and puts them first" and "I trust my doctor to tell me if a mistake was made about my treatment". Example of negatively worded questions would be "I feel my doctor does not do everything he/she should for my medical care" and "I doubt that my doctor really cares about me as a person.” Although the scale has not been specifically validated in a LS population, it has been validated with primary care patients and has been shown to have high internal consistency (Cronbach's $\alpha=.89$ ), and good 1-month test-retest reliability (intraclass correlation coefficient $=$ .77; Thom, Ribisl, Stewart, Luke, 1999). The internal consistency for this scale was comparably high in the current study (Cronbach's $\alpha=.84$ ). 


\section{Data Analysis}

Multiple regression analyses were conducted to test the relationship of predictors (intolerance of uncertainty and prior cancer diagnosis) with the outcomes of cancer worry and medical service utilization, after adjusting for known demographic and medical covariates of the outcomes. For example, younger age, less education, and an increased number of family members affected by cancer (Consedine et al., 2004) have all been show to predict higher cancer worry, while female sex (Green \& Pope, 1999), and Caucasian ethnicity (Andersen \& Newman, 2005) have been shown in prior studies to be associated with greater medical utilization.

To examine whether trust in physician moderated the above mentioned relationships, multiple regression analyses using a macro called MODPROBE for SPSS (developed by Hayes \& Matthes, 2009) were conducted. The MODPROBE macro is advantageous compared to typical hierarchical regression techniques, in that it allows for probing of significant interactions within the program. For example, the macro examines the conditional effect of the moderator variable at various levels, such as the sample mean, and at one standard deviation above and below the sample mean. The Johnson-Newman (J-N) technique is a method used to probe interactions in linear models, which examines the boundary conditions of the effect to understand for whom and under what conditions the effect exists. Specifically, the J-N technique demarcates regions in the range of the moderator variable where effect of the predictor on the outcome is significant and not significant.

\section{Power Analyses}

The current project used secondary data from a larger study. Therefore, we calculated power using our most comprehensive model, which was a multiple regression analysis with four covariates (age, education, number of first degree relatives diagnosed with LS, and number of all 
relatives diagnosed with cancer), two main predictor variables, and one interaction term. Using our actual $N=128$ with an obtained R-squared of 0.24 , power was at $92 \%$ (with alpha $=.05$ ).

\section{Results}

\section{Preliminary Analyses}

Prior to analysis, the data were screened for outliers and assumptions of normality and linearity were tested. The screening revealed that the data for the key variables (i.e., intolerance of uncertainty, number of prior cancer diagnoses, trust in physician, medical service utilization, worry interference) all had non-normal distributions according to the recommendation that the skewness statistic be divided by its standard error and the resulting z-score should fall between $\pm 2.58(\mathrm{p}<.01)$ to ensure minimal skewness (Field, 2009). Therefore, each variable was transformed using square-root and logarithmic transformations. However, the transformations were ineffective at reducing skewness and thus the analyses were performed using nontransformed data.

\section{Participant Demographics}

A total of 128 women with a confirmed diagnosis of LS were included in the analysis (all demographic characteristics of the sample are displayed in Table 1). The majority of the women in the sample were white (90.6\%), employed (60.2\%), married or partnered (79.7\%), and university educated or higher (76.6\%). Participants ranged in age from 23 to 86 years old with a mean age of 52.53 years $(S D=14.49)$.

\section{See Table 1}

The majority of the sample had been previously diagnosed with some type of cancer $(n=$ $79,62.0 \%)$, with the mean age of $43.37(S D=9.91)$ at the time of the first diagnosis, and range 
between 22 and 66 years old. Among those diagnosed with cancer, the mean number of years since the first cancer diagnosis and date of completion of the questionnaire was 16.19 years (SD $=11.98$ ), and the number of times diagnosed with cancer ranged from 1 to 5 with a mean of 1.2 $(S D=1.37)$ diagnoses per individual. The most commonly reported cancer in this sample was colorectal cancer, followed by endometrial cancer, which are the two cancer sites of highest risk in individuals with LS (Aarnio et al., 1999). Detailed information about the type of cancer, frequencies of diagnoses, and the number of cancers with which individuals were diagnosed is found in Table 2.

See Table 2

Information regarding family history of LS and cancer was collected from the FGICR database. For this sample, the mean number of relatives diagnosed with LS was 4.60 (SD = 2.72), with a range between 1 and 12 relatives, and among those relatives a mean of 1.54 ( $S D=$ 1.24) were first degree relatives, with a range of 0 to 6 . Furthermore, participants had a significant family history of cancer. Specifically, the mean number of first degree relatives diagnosed with cancer was $2.18(S D=1.47)$, ranging from 0 to 7 .

\section{Descriptive Information on Key Variables}

Medical Service Utilization. In total, 110 participants (85.9\%) indicated that over the past six months they attended at least one medical appointment, with an average of $3.79(S D=$ 3.23 , range $=0-16$ ) medical visits per person. General practitioners were the most commonly utilized for medical visits (96 visits, $M=1.97, S D=1.45$, range $=0-10$ ), followed by gastrointestinal specialists (40 visits, $M=.95, S D=.60$, range $=0-2$ ), surgeons (36 visits, $M=$ 
$.68, S D=1.42$, range $=0-5$ ), gynecologists (27 visits, $M=1.00, S D=.83$, range $=0-4$ ), oncologists (26 visits, $M=.92, S D=.85$, range $=0-3$ ), other specialists (26 visits, $M=1.88, S D$ $=1.18$, range $=1-5)$, emergency room (25 visits, $M=1.16, S D=1.18$, range $=0-4)$, genetic counsellors (19 visits, $M=.58, S D=.61$, range $=0-2$ ), and cardiologists (12 visits, $M=.50, S D$ $=.80$, range $=0-2)$.

Worry Interference. The summed mean score on the Worry Interference Scale was 9.48 $(S D=3.75)$ with a range of 7-23 out of a possible range of 7-35. The mean score reflects that participants reported, on average, "a little” cancer-specific worry that interfered with their ability to function in their daily lives. Among the seven individual items, mean scores ranged from 1.181.48, demonstrating that no one item disproportionately accounted for overall worry interference.

Intolerance of Uncertainty. The mean score for our sample was $2.47(S D=.70)$, with a range of 1.08-4.58, out of a possible range 1-5. The large range within this sample is also reflected in the mean, which reveals that there were some participants who were very high in intolerance of uncertainty and some that scored very low. However, on average, individuals reported that statements reflecting a difficulty tolerating uncertainty were a "little or somewhat characteristic of me”, and overall this sample demonstrated a moderate amount of intolerance of uncertainty.

Number of Prior Cancer Diagnoses. The mean number of reported prior cancer diagnoses in the current sample was $1.2(S D=1.37)$ with a range of $0-5$.

Trust in Physician. The mean was $3.52(S D=.57)$, with a range of $1.55-4.91$ out of a possible range of $1-5$. This means that there was a relatively good variability of scores within this sample, however on average, most individuals reported that they "agree" with statements 
reflecting trust in their physician on various items such as competency, confidentiality, and respect.

\section{Tests of Hypotheses}

Aim One: To examine the relationship of intolerance of uncertainty with the outcomes of worry interference and medical service utilization.

Hypothesis 1a. A regression analysis tested the hypothesized effect of intolerance of uncertainty (IUS total) on worry interference (WIS total). Table 3 displays the standardized betas, standard errors, $R^{2}$, adjusted $R^{2}$ and $R^{2}$ change values. In Block 1 , covariates (age, education level, number of all relatives diagnosed with cancer, and number of first degree relatives diagnosed with LS) were entered into the model. There was no statistically significant effect of these covariates on worry interference, $F(4,110)=1.23, p=0.301$. In Block 2 , intolerance of uncertainty was entered into the model and had a statistically significant effect, $F(1,109)=4.70, p=.001$, accounting for $14 \%$ of the variance of worry interference $\left(R^{2}=0.18\right.$, $R^{2}$ adj $\left.=0.14\right)$, with a greater IUS total score associated with higher WIS total score $(\beta=.38, S E$ $=.43, p=.001)$.

\section{See Table 3}

Hypothesis 1b. A second regression analysis tested the hypothesis that there would be a significant relationship between intolerance of uncertainty and medical service utilization. The covariates mentioned above were entered into the model in Block 1, and the model was not statistically significant, $F(4,98)=1.87, p=.321$. However, the variable "number of all relatives diagnosed with cancer” had a significant effect on medical service utilization, such that 
a higher number of relatives diagnosed with cancer was statistically significantly associated with a lower number of medical visits reported $(\beta=-.22, S E=0.03, p=.033)$. Intolerance of uncertainty was added in Block 2 and was not statistically significant, $F(5,97)=1.02, p=.411$. Table 4 shows these non-statistically significant findings.

See Table 4

Aim Two: To examine the relationship of the number of prior cancer diagnoses with the outcomes of worry interference and medical service utilization.

Hypothesis 2a. To test the extent to which the number of prior cancer diagnoses would be associated with worry interference, a regression analysis was conducted. The abovementioned covariates were entered into the model in Block 1, and overall there was no significant effect on the model, $F(4,112)=1.37, p=.249$. In Block 2, number of prior cancer diagnoses was entered into the model, and there was a significant effect on worry interference, $F(5,111)=3.710, p=.004$, accounting for $11 \%$ of the variance $\left(R^{2}=0.14, R^{2}\right.$ adj $\left.=0.11\right)$, with a higher number of times diagnosed with cancer associated with higher WIS total score $(\beta=.39$, $S E=.29, p=.001)$. In addition, when number of times diagnosed with cancer was entered into the model, age became statistically significant as well, with younger age associated with more worry interference $(\beta=-.34, S E=.0 .27, p=.002)$. Table 5 displays these significant findings.

See Table 5 
Hypothesis 2b.The next regression tested the hypothesized relationship between a greater number of prior cancer diagnoses and more medical service utilization. Covariates were once again entered into Block 1, and the overall model was not significant, $F(4,100)=1.29, p=$ .278. Only number of all relatives diagnosed with cancer was significantly associated with medical service utilization $(\beta=-.22, S E=0.32, p=.027)$, such that having a greater number of relatives diagnosed with cancer was associated with less medical visits. In Block 2, number of prior cancer diagnoses was entered and the overall model was significant, $F(5,99)=2.86, p=$ 0.19 , with greater number of times diagnosed with cancer associated with a greater number of total medical visits reported, $(\beta=.35, S E=.0 .26, p=.004)$. It is notable that number of all relatives diagnosed with cancer remained significant in Block $2(\beta=-.21, S E=0.31, p=.034)$. Table 6 displays these significant findings.

See Table 6

Aim 3: To examine trust in one's physician as a moderator of the relationship between the predictors (intolerance of uncertainty and number of prior cancer diagnoses) and the outcomes of worry interference and medical service utilization

Hypothesis 3a. It was hypothesized that people who have greater trust in their physician will be buffered against the effects of intolerance of uncertainty on the outcomes of worry interference and medical utilization compared to those who have less trust in their physician. Moderation analyses, using the MODPROBE macro, revealed that the association between intolerance of uncertainty and worry interference was moderated by trust in one’s physician (controlling for above mentioned covariates), $F(7,99)=5.1488, p=.03$. This was demonstrated 
by a significant interaction term of intolerance of uncertainty $\mathrm{X}$ trust in one's physician (see Table 7). Figure 4 displays the interaction effect at one standard deviation below the mean, at the mean, and above the mean of the moderator (i.e., low, moderate or high values). As can be seen, the significant effect indicates that women who have greater intolerance of uncertainty but who have more trust in their physician report less worry interference compared to women who have greater intolerance of uncertainty and less trust in their physician, who report the highest amount of worry interference. The J-N technique showed the significant effect of intolerance of uncertainty on worry interference occurred at 0.36 on the trust in physician scale, which is just slightly less than one standard deviation above the mean. Table 7 shows the significant interaction of intolerance of uncertainty and trust in physician, $b=-1.39, t(99)=-2.27, p=.03$. The coefficient for the interaction means that as trust in physician increases by one unit, the coefficient for intolerance of uncertainty decreases by -1.39 . This suggests that respondents who had less trust in their physician reported more cancer-specific worry interference when they had higher intolerance of uncertainty. For the second outcome of medical utilization, moderation analyses did not show that the association between intolerance of uncertainty and medical service utilization was significantly moderated by trust in one's physician, $F(7,87)=2.00, p=$ .16 Table 8 shows these non-statistically significant findings.

See Table 7

See Figure 4 
See Table 8

Hypothesis 3b. It was hypothesized that individuals with more trust in their physician will also be buffered against the effects of number of prior cancer diagnosis on the main outcomes (worry interference, medical service utilization) relative to those with less trust in their physician. Moderation analyses demonstrated that trust in one’s physician did not significantly moderate the association of prior cancer diagnosis and worry interference, $F(7,99)=.9923, p=$ .3216. For the second outcome of medical utilization, analyses did not show that the association between prior cancer diagnoses and medical service utilization was significantly moderated by trust in one's physician, $F(7,87)=3.0166, p=.086$. Tables 9 and 10 show these non-statistically significant findings, respectively.

See Table 9

See Table 10

\section{Discussion}

\section{Summary of Findings}

Findings showed that greater intolerance of uncertainty and higher number of prior cancer diagnoses was associated with more cancer-specific worry interference. As predicted, prior cancer diagnosis was associated with more medical service utilization, but contrary to our 
hypotheses, intolerance of uncertainty was not significantly associated with this outcome. In addition, trust in physician was found to moderate the relationship between intolerance of uncertainty and worry interference, however it did not moderate the relationship between either predictor (intolerance of uncertainty and prior cancer diagnosis) and medical service utilization.

\section{Predictors of Cancer-Specific Worry Interference}

\section{Intolerance of uncertainty as a predictor of cancer-specific worry interference. To}

examine whether the current participants differed from those of previous research, mean scores for the current study were compared to other hereditary cancer samples. The current sample’s worry interference scores $(M=9.48, S D=3.75)$ were comparable to those published for women at high risk for breast and ovarian cancer $(M=10.47, S D=4.58)$ (Trask et al., 2001). To date, two studies have used the worry interference scale and have both yielded comparable data. In a study on women with BRCA mutations undergoing MRI surveillance, scores on the worry interference scale were almost equivalent to our sample at baseline (1-2 weeks before surveillance screening; $M=9.8, S D=3.7)$ and at six months after screening $(M=9.4, S D=3.2$; Spiegel et al., 2011). Another study investigating psychological outcomes among individuals at increased risk for cancer found a slightly lower mean among carriers of a cancer susceptibility gene mutation $(M=8.19, S D=3.5$; Shiloh, Drori, \& Orr-Urtreger, 2009). However, it is important to note that none of the participants in the Shiloh et al. (2009) study had ever been diagnosed with cancer. Although worry interference was not severe for most participants in the current study, the average participant experienced cancer worry that interfered "at least a little" in several areas of their daily functioning. The areas in which cancer-specific worries interfered the most were the ability to concentrate, the decision to have children, feeling sexually attractive, and thinking about offspring developing cancer. 
As expected, more intolerance of uncertainty significantly predicted greater worry interference. This is consistent with findings from the BRCA1/2 literature showing that greater intolerance of uncertainty is associated with higher cancer-related distress (O’Neill et al., 2006). The mean score on the intolerance of uncertainty scale in the O'Neill (2006) study was slightly lower but generally comparable $(M=1.85, S D=0.70)$ to our sample $(M=2.47, S D=0.70)$. Additionally, a recent study of the impact of intolerance of uncertainty on psychological adjustment in lung cancer patients produced a similar mean score on this scale $(M=1.87, S D=$ 0.29; Kurita, Garen, Stanton, \& Meyerowitz, 2012). Kurita and colleagues (2012) demonstrated that in this cancer sample, higher intolerance of uncertainty was associated with poorer emotional well-being, higher perceptions of stress and explained a noteworthy proportion of the variance in poor psychological adjustment.

Aside from these two studies, the extant literature on uncertainty in health populations and more specifically familial cancer populations seems to focus on situational uncertainty, using measures such as Mishel’s Illness Uncertainty Scale, which refers to aspects of the health condition, such as the seriousness of the condition, one's vulnerability or risk, treatment efficacy and prognosis (Mishel, 1981) instead of traits or individual tendencies to process health threats. Therefore, this study is one of the first to examine how individuals are affected by the unknown outcome of a health threat (intolerance of uncertainty). Our data support the notion that individual differences in intolerance for uncertainty may help elucidate individuals at risk for elevated cancer-specific worry that interferes with their daily lives. However, as we did not measure levels of intolerance of uncertainty in our sample prior to receiving a positive mutation status or prior to their cancer diagnosis, it is also possible that these events may serve to increase one's intolerance of uncertainty and subsequent distress. Measuring intolerance of uncertainty 
pre and post genetic counseling/cancer diagnosis may help clarify this finding. Our data, taken together with a few other extant studies, demonstrate the potential utility of using intolerance of uncertainty to help predict long-term adaptation to being an LS mutation carrier, however future research in this area is needed.

Prior cancer diagnosis as a predictor of cancer-specific worry interference. Having a higher number of past cancer diagnoses also predicted greater cancer-specific worry interference, as hypothesized. This is concordant with previous research suggesting that amongst high risk women, those with a cancer history may be an emotionally vulnerable subset (Bish et al., 2002; Kasparian et al., 2008; van Roosmalen et al., 2004). However, those studies only examined whether or not women had experienced cancer and not the additive effect of several cancer diagnoses, as we did in the current study. As such, future research may benefit from assessing the number of prior diagnoses as opposed to inquiring categorically as to whether someone has a cancer history, as the risk of distress appears to increase with the number of cancer diagnoses.

In addition to number of cancer diagnoses, younger age was also related to worse cancerspecific worry interference. Importantly, the majority of the sample had been previously diagnosed with some type of cancer $(n=79,61.7 \%)$, with the mean age of $43.37(S D=9.91)$ at the time of the first diagnosis, and range of between 22 and 66 years old. This is a particularly young age of onset compared to the general population, as research has shown that the median age at diagnosis for cancer of all sites to be 66 years of age, with $76.8 \%$ of diagnoses occurring after age 55 (Howlader et al., 2013). This is consistent with one of the defining characteristics of genetic cancers - a younger age of diagnosis — and also supports extant research showing that younger age is associated with increased distress in women with a familial cancer history (Engel et al., 2003; Kerr et al., 2003; Scholefield et al., 2003). Taken together, findings from Aim 1 
help to clarify predictors of cancer-specific distress in women with LS. Collecting information about intolerance of uncertainty and prior cancer diagnosis may be valuable for identifying individuals who would benefit from additional support.

Lastly, although our model, consistent with the model of hypochondriasis, posited that distress in the form of worry interference is maladaptive and problematic, it is also possible that worry has an adaptive function. Specifically, experiencing increased worries may motivate one to engage in cancer screening behaviors and proper surveillance (Cameron, Leventhal, \& Leventhal., 1995; Diefenbach \& Leventhal 1996). This was not a focus of the current study, but is important to consider for future research among women with LS.

\section{Predictors of Medical Utilization}

Intolerance of uncertainty as a predictor of medical utilization. Contrary to our hypotheses, intolerance of uncertainty was not significantly associated with medical utilization. We had expected this association based on prior data showing that experimentally inducing high intolerance of uncertainty about a health threat leads to increased information-seeking, and that those with anxiety disorders have increased use of medical services compared to the general population (e.g., Kennedy \& Schwab, 1997). Furthermore, a study by Marciniak and colleagues (2004) found that outpatient medical utilization among matched healthy controls was 50\% lower compared to anxiety disorder patients across numerous medical specialties. Some possibilities for the lack of a relationship between intolerance of uncertainty and use of medical services may be that: 1) intolerance of uncertainty may not be the feature of anxiety that is driving medical utilization or 2) medical services are not being inappropriately used by this high risk sample.

The mean total number of medical visits for the last six months reported in our sample ( $M$ $=3.79, S D=3.23$ ) was comparable to that for anxiety disorder patients, who averaged three 
outpatient medical visits in the prior six months (Deacon, Lickel, \& Abramowitz, 2008). Our sample also evidenced a comparable intolerance of uncertainty mean score compared to other research on GAD patients (Holaway, Heimberg, \& Coles, 2006; Lee, Orsillo, Roemer, \& Allen, 2010; Yook, Kim, Suh, \& Lee, 2010), and much higher intolerance of uncertainty scores than those reported by non-anxious controls (Holaway et al., 2006). Given that our sample was equivalent to patients with GAD on intolerance of uncertainty as well as highly comparable in number or medical visits reported, it is possible another feature of GAD, such as the experience of physical symptoms, accounts for medical utilization. For example, investigation into the high rates of medical utilization in panic disorder have suggested that it is the distressing and often spontaneously occurring physical symptoms that prompt patients to seek medical attention (Deacon et al., 2008). In accordance, there are many physical symptoms associated with GAD (sleep disturbances, fatigue, restlessness, difficulty concentrating) that overlap with medical conditions that may be motivating the increased medical utilization.

Prior cancer diagnosis as a predictor of medical utilization. A second, and perhaps more relevant explanation, is that medical utilization is being driven by other factors, such as that more than half of our sample are cancer survivors. As expected, greater number of times diagnosed with cancer was associated with a greater number of total medical visits reported. This finding is in line with extensive literature that demonstrates that individuals with a cancer history often utilize more medical services than their age-matched counterparts (e.g., Hewitt et al., 2003; Roorda et al., 2012; Stafford \& Cyr, 1997). Although we were not able to locate comparable research on the specific number of medical visits in a given year for other cancer populations, one study (Lorig et al., 2001) found that chronic disease patients (e.g., heart and lung disease, stroke, arthritis) made 5.17 visits to the ER and to family doctors in the prior year. 
Therefore, if we extrapolate the number of visits (reported over six months by our participants) to one year, they appear comparable to those with other chronic illnesses. However, it was not possible to identify whether the increased use of medical services among those with more cancer diagnoses was due to medical comorbidities, psychological factors, or a combination of the two. As the economic burden of increased cancer survivorship is becoming progressively more substantial, future research in the factors that are motivating the increased utilization of services would be beneficial.

A final consideration relates to the limitations of the measure used to assess medical service utilization. One limitation of the measure used is that we did not assess whether each visit to each medical setting was a regularly scheduled appointment or whether the utilization was above and beyond these scheduled visits. Furthermore, although extensive data show good concordance between self-report and electronic record (Bhandari \& Wagner, 2006; Ritter et al., 2001; Robinson, Young, Roos, \& Gelskey, 1997) perhaps using electronic records would have reduced the possibility of error in reporting. Although there could have been improvement in the measure, it is also possible that participants used appropriate medical services given that this is a high-risk sample.

It is worth noting that an unexpected finding emerged in our tested model of medical utilization. Specifically, we found that having more relatives diagnosed with cancer significantly predicted less medical utilization. Qualitative research into the experience of being high-risk for developing cancer has demonstrated that women use their family history and family experiences with cancer as reference points for navigating their own cancer experience (Bernhardt et al., 1997; Geller, Strauss, Bernhardt, \& Holtzman, 1997). Furthermore, d’Agincourt-Canning (2005) demonstrated that individuals at high risk for breast and/or ovarian cancer reported that their 
personal experiences in living with or caring for relatives who have had cancer were important determinants in their own management of cancer. For example, women reported acquiring their knowledge of cancer, its symptoms and particular manifestations, the side effects of treatment and the likelihood of survival directly from their family history and experiences with cancer. Therefore, it is possible that individuals with an extensive family history of cancer rely on the knowledge they have acquired through personal experience with the disease as opposed to seeking the knowledge from medical professionals. It is also possible that having more family members diagnosed with cancer increases one's anxiety and subsequently leads to avoidance behaviors, such as avoiding medical appointments. Beyond this speculation, the reason for this association remains unclear.

\section{Moderating Effect of Trust in Physician}

The role of physician trust in the association between intolerance of uncertainty and the outcomes (cancer-specific worry interference and medical utilization). As predicted, having more trust in one's physician buffered the impact that being high in intolerance of uncertainty had on worry interference. This is in line with research on the beneficial outcomes associated with having trust in one’s physician, such as decreased psychological distress (e.g., Bloom, Stewart, Johnston, Banks, \& Fobair, 2001). One possible explanation for the impact of effective physician communication and more positive health outcomes is that viewing one's physician as a credible source of information (e.g., informational support) reduces feelings of uncertainty around one's health (Padilla et al., 1992). As such, having a positive appraisal of communication with one's physician may help protect individuals with LS from the negative outcomes and uncertainty associated with the knowledge of having a heightened vulnerability to many cancers. Furthermore, research into the specific elements that have been found to reflect 
effective interaction between patient and physician (e.g., compassion, reliability and dependability, privacy and confidentiality; Bakker, Fitch, Gray, Reed, \& Bennett, 2001;

McWilliam et al., 2000) suggests that trust in one’s physician can be conceptualized as a form of social support.

Consistent with this conceptualization, the "buffering hypothesis" states that social support "serves to protect people from the negative consequences of stressful life events by positively influencing how people think about and cope with the events” (Lazarus \& Folkman, 1984). Research has shown that cancer patients often seek reassurance from their physicians (Rose, 1990; Takayama, Yamazaki, \& Katsumata, 2001) due to the many uncertainties associated with the disease and its treatment. Indeed, physical symptoms, even benign ones, can serve as reminders of patient' vulnerabilities and therefore may increase their anxiety (Easterling \& Leventhal, 1989). In turn, some patients may attempt to reduce their anxiety by seeking reassurance about their symptoms from their physician (Barsky, Ettner, Horsky, Bates, \& 2001; Lee-Jones, Humphris, Dixon, \& Hatcher, 1997). As such, beyond seeking medical information, research suggests that patients often turn to their healthcare provider for support needs, which if met, greatly reduces the disruption to their QOL (Rose, 1990; Schain, 1990). Accordingly, having trust in one's physician may reduce feelings of uncertainty and the interference of cancer worry, which is particularly beneficial to those who have high intolerance of uncertainty. Additionally, it is possible that patients are not actually seeking "reassurance," which implies the repeated use of medical services to remove their health-related doubts or worries, but rather that patients are seeking assurance and /or appropriate amounts of health-related information, given the constantly-evolving medical guidelines for proper cancer surveillance in LS. There is currently no measure available that would allow for the distinction between information-seeking 
as a distress-reduction behavior (i.e., reassurance-seeking) and seeking information to better understand and manage the illness and its symptoms (i.e., assurance-seeking). In order to increase our understanding in this area future research would benefit from using open-ended questions or semi-structured interviews.

Contrary to expectations, trust in physician did not moderate the relationship between intolerance of uncertainty and medical service utilization. This is not surprising considering the finding that intolerance of uncertainty was not significantly associated with medical utilization. As noted earlier in the discussion, if the reported medical visits were necessary and appropriate, it is possible trust in one's physician would bear little impact on this variable.

The role of physician trust in the association between prior cancer diagnosis and the outcomes (cancer-specific worry interference and medical utilization). Additionally, having trust in one’s physician did not moderate the relationship between prior cancer diagnosis and cancer-specific worry interference. A potential explanation is that one's personal experience with being diagnosed and treated for cancer has a stronger impact on the extent to which cancerspecific worry interferes with their life than does their trust in their physician. Therefore, having been through the process of cancer treatment may increase the amount that one worries about cancer regardless of how much they trust their physician. This would be consistent with the extensive literature on fear of recurrence, which has documented that most cancer survivors worry about their cancer coming back (Baker, Denniston, Smith, \& West, 2005; Simard \& Savard, 2009; Lebel, Rosberger, Edgar, \& Devins, 2007; Llewellyn, Weinman, McGurk, \& Humphris, 2008). Fear of recurrence is associated with numerous negative outcomes, such as increased distress and anxiety, and poorer quality of life (Bellizi, Latini, Cowan, DuChane, \& Carroll, 2008; Hong, Hu, Paciorek, Knight, \& Carroll, 2010), and has been found to be the most 
frequently cited unmet need among cancer survivors (Baker et al., 2005). It is therefore possible that such a strong fear would not be tempered by simply having more trust in one’s physician. Furthermore, trust in physician did not moderate the relationship between prior cancer diagnoses and medical service utilization. As greater number of prior cancer diagnoses was associated with more medical utilization, it is possible, as was previously discussed, that the utilization was appropriate based on the degree of illness. Therefore, the degree of trust in one's physician would have little impact on this relationship.

On a final note, it is possible our findings might have differed if we had measured trust more broadly. Because many of the participants in this sample have been treated for cancer, we may have limited information about patients' trust in their health care team as our measure was restricted to only examining trust in one's general practitioner. Indeed, the team composition will vary by cancer type, but can include surgeons, diagnostic and therapeutic radiologists, histopathologists, medical and clinical oncologists, nurse specialists, and palliative care physicians (Fleissig, Jenkins, Catt, \& Fallowfield, 2006). There is no existing measure on satisfaction with the entire healthcare team, but researchers may consider developing such a measure given that trust may differ depending on who is being evaluated by the patient, and therefore may affect outcomes differently.

\section{Study Limitations}

Limitations of the present study are important to consider when interpreting these findings. First, certain psychometric problems may have impacted the results, specifically issues of scale reliability and validity. As mentioned earlier, limitations of the medical utilization measure may have played a role in the lack of findings for this outcome. Furthermore, although even low scores on the worry interference scale reflect that cancer-specific worry is interfering 
with one's daily functioning in many areas, it is possible that a more sensitive measure could have captured a more accurate picture and provided more information about the impact of experiencing cancer-specific worries. Additionally, although the measures in this study have all been validated with clinical samples (Trask et al., 2001; Carleton Collimore, \& Asmundson, 2010; Anderson \& Dedrick, 1990) they have yet to be used in research examining LS patients. None of the measures have been psychometrically validated in this population. Additionally, there is no psychometric data available at all for the medical utilization measure. Given these limitations, it is possible that the measures did not clearly and comprehensively tap into the issues that matter most to LS patients. Consequently, it is possible that the constructs were only weakly captured, thereby potentially reducing power.

A second limitation lies in the generalizability of our findings. The sample consisted of women who had all sought genetic testing, were part of the FGICR database and agreed to participate in additional research, and also agreed to participate in our specific study. This selfselected sample might therefore not be representative of the larger population of women with LS. However, participants were not found to significantly differ from other published samples of LS on any demographic variable or medically-relevant data (Landsbergen et al., 2012; Aktan-Collan et al., 2013). Moreover, our sample was primarily Caucasian, highly educated, employed and relatively affluent; therefore it is unknown whether these findings would be replicated in a lower income, less educated or non-Caucasian sample. Indeed, there are no data that exist on random samples in LS. Extrapolating from studies on other representative cancer populations, lower income and less education tend to be associated with higher distress levels and poorer adjustment (Hoffman et al., 2001; Kash, Holland, Halper, \& Miller, 1992) 
In addition, only 128 out of the 204 eligible patients in the FGICR registry completed the questionnaire, which translates into a response rate of $67.2 \%$. However, our response rate is consistent with other research utilizing self-report formats with participants recruited from cancer registries, which is commonly 50-65\% (Esplen et al., 2007; Esplen et al., 2001). Unfortunately, we did not have access to data that would have allowed for a comparison of nonresponders to responders, so we cannot comment on how this may have further impacted generalizability.

Furthermore, the J-N technique that was used to examine moderation in our model is relatively exploratory. Specifically, the regions of the moderator where the effect of the predictor on the outcome is significant versus non-significant is not examined based on a theoretical hypothesis. Instead, that region is determined statistically. An alternative to the J-N technique is the "pick-a-point" approach to probing interactions, which requires the a priori identification of that region of the moderator variable and estimate of the size of the focal predictor at that point on the moderator. A hypothesis test is then conducted or confidence intervals are constructed to determine whether the effect of the focal predictor is different from zero at that selected point (Hayes \& Matthes, 2009). Due to the lack of previous literature in this area to determine this point, we felt the exploratory nature of the J-N technique was appropriate. An important future direction is to accumulate an adequate amount of research to guide an empirically-based examination using the pick-a-point approach.

A final limitation is that data were collected cross-sectionally and therefore cannot be used to infer causality. Among those diagnosed with cancer, which was over half of the sample, the mean number of years since the first cancer diagnosis and date of completion of the questionnaire was 16.19 years. Therefore, these findings may not be replicated in samples of 
women who are at different phases of their diagnosis, treatment and/or survivorship.

Furthermore, given the number of women in our sample with a prior cancer diagnosis, we did not have the statistical power to examine individuals at high-risk without a cancer history.

\section{Future Directions and Theoretical Considerations}

The model of hypochondriasis was used as a guiding conceptual framework as it suggests that dysfunctional illness beliefs, including intolerance of uncertainty, activate illness-specific fears and motivate safety/support seeking behaviors. As such, cancer-specific worry interference and medical service utilization were examined as psychological and behavioral manifestations of distress, respectively. This model helped increase our understanding of cancer-specific worry interference in women with LS. Although intolerance of uncertainty was associated with increased cancer-specific worry interference, there may be other important dysfunctional beliefs to examine. Specifically, the hypochondriasis model suggests that beliefs such as overestimating one's risk of the disease and interpreting a health condition as harmful and threatening may also trigger worry and fear. Therefore, future research may benefit from assessing perceived risk and appraisals in order to further our understanding of factors that predict worry interference. Despite the fact that there are other models that help to understand health beliefs and behaviors, such as the common sense model (Leventhal, Meyers, \& Norenz, 1980) and the health belief model (Becker \& Maiman, 1975), they are not specifically focused on disease related worry.

One conceptual framework that does specifically look at worry (but not a behavioral manifestation of distress, such as medical utilization), the model of disease-specific worry in heritable diseases, has suggested that factors such as family history of disease, perceived risk of the heritable disease, and perceived risk about other diseases predict increased disease-specific worry in men and women at high risk of breast, prostate and colon cancer (DiLorenzo et al., 
2006). Our study builds upon these findings and demonstrates that having personal history of cancer is associated with increased cancer-specific worry interference above and beyond having a family history of cancer, and that this illness-specific distress increases with greater number of cancer diagnoses. Additionally, worrying about developing diseases other than those for which one is high risk has been found to be associated with increased worry (Schnur et al., 2006). This suggests that worrying more generally about the possibility of developing any disease may predict more cancer-related worry, which is consistent with the model of hypochondriasis.

Furthermore, although perceived risk has been found to mediate the relationship between family history and disease-specific worry, perceived risk has been found to be resistant to change in high risk populations, who often continue to overestimate their risk after receiving genetic counseling (Watson et al., 1999). However, our study has elucidated a novel moderator in the relationship between having a personal history of cancer and cancer-specific worry interference that may be amenable to intervention. Outlining a predictive model of worry about disease is important due to its association with health outcomes and ability to disrupt ones functioning in numerous areas of daily life. Based on extant literature and the findings from this study, examining perceived risk and appraisals (as suggested by the model of hypochondriasis) may further our understanding of predictors of cancer-specific worry interference.

While our model helped us gain a better understanding of worry interference, the findings from this study suggest that it may be more appropriate to use another conceptual framework to examine medical utilization. Health policy models are used to explain determinants of health care utilization and to help understand reasons for use and overuse of services. For example, the Andersen model (Andersen, 1995), commonly used in chronically ill populations, posits that there is a sequential relationship between three types of determinants and service use: (1) a 
predisposition to use services (i.e., predisposing factors, including demographic and socioeconomic variables) (2) an ability to obtain services (i.e., enabling factors, such as income, insurance, characteristics of the health care system) and (3) medical need (i.e., need factors, including both professionally assessed needs and perceived needs). Furthermore, research suggests that mental health status is also important to consider within this model, as depression and anxiety in particular have been to shown to be linked to higher rates of health care utilization (Hays, Wells, Sherbourne, Rogers, \& Spritzer, 1995; Barsky, Delamater, \& Orav, 1999; Zane, McAfee, Sherburne, Billeter, \& Barsky, 2003). As such, future research on the determinants of medical service utilization in LS would benefit from using a framework such as the Andersen model and incorporating measures of psychological health status, specifically anxiety and depression, to more accurately and comprehensively take into account the many factors that play a role in their health care utilization.

\section{Clinical Significance}

Despite the aforementioned limitations, data obtained from the present study have implications for patients, healthcare providers, and researchers. The current study identified that individuals who have higher intolerance of uncertainty and/or a history of cancer may be particularly vulnerable to increased distress. This is the first study to investigate intolerance of uncertainty as a predictor of poor adjustment in a sample of women with LS. This may assist the early identification of women who may need additional support; however, further research in this area is needed. Furthermore, this study has extended the current literature on high risk women by suggesting that not only does having a cancer history potentially predispose one to higher illness-related distress, but the number of times that one has been diagnosed with cancer has an incremental impact. Overall, this study has identified two important individual difference 
variables that may allow for the detection of especially vulnerable high risk women with LS. As the research on genetic counseling moves beyond the impact of testing and extends to issues of long term adjustment to living as a mutation carrier, these variables warrant further research investigation in order to help health care providers better identify individuals who are increased risk for distress.

This study has also demonstrated that having more trust in one’s physician can help buffer the impact of higher intolerance of uncertainty on worry interference. This is important information for health care providers, such that being a form of social support for high risk patients who have more difficulty dealing with uncertainty may dramatically reduce the impact that their status has on their daily lives. It is only in recent years that testing for genetic susceptibility genes has entered the clinical setting, requiring the practicing physician to be familiar with this evolving and quickly expanding area of medicine and to be able to manage and/or refer high-risk patients to other specialists if/when necessary. Accordingly, although empirical data are scarce on this issue, anecdotal evidence from our FGICR patients has suggested that many individuals with LS do not feel that their family physician (general practitioner) knows enough about LS. Indeed, a study examining primary care physicians’ knowledge and attitudes toward genetic testing revealed concerning support for this apprehension. Escher and Sappino (2000) surveyed a large sample of primary physicians, internists, obstetrician-gynecologists and oncologists on their knowledge about hereditary breastovarian cancer. Although the majority of the primary care physicians reported being in favor and capable of playing a prominent role in genetic counseling and testing, physicians only answered a third (32\%) of the knowledge questions correctly. This finding suggests patients' concerns 
may not be unfounded and highlights the need for the implementation of targeted educational programs for physicians.

As susceptibility genes continue to be identified and testing becomes more common place, there is likely to be a strong interest in knowing one's genetic status among the population (Lerman, Daly, Masny, \& Balshem, 1994; Chaliki et al., 1995) and individuals will turn to their physicians for information and counseling. This is a substantial responsibility for the physician to bear, as they are required to know the potential limitations, risks and benefits of testing, the options for medical surveillance as well as confidentiality regulations (Tambor, Rimer, \& Strigo, 1997; Biesecker et al., 1993; Murday, 1994). This constitutes a dramatic extension to the standard medical consultation most physicians were trained in and have been employing throughout their practice. Beyond evaluating familial cancer risk and providing counseling accordingly, special consideration to the emotional and psychological needs and moral values of individuals is required in order to help them make an informed decision.

Consequently, a clear priority is to better educate physicians so they are able to perform the comprehensive tasks involved in genetic counseling and testing, which may in turn serve to increase patients’ trust in their physicians’ ability to manage their LS. However, the current study also highlighted the impact that having trust in one’s physician can have on the daily experience of intrusive cancer-specific worries, which suggests that the supportive aspect of the counseling should also be a priority. Future research in the area of physician trust would be helpful in gaining more insight about how it can be improved from the patients' perspective. 


\section{References}

Aarnio, M., Sankila, R., Pukkala, E., Salovaara, R., Aaltonen, L. A., de la Chapelle, A., ... Järvinen, H. J. (1999). Cancer risk in mutation carriers of DNA-mismatch-repair genes. International Journal of Cancer, 81(2), 214-218. doi: 10.1002/(SICI)10970215(19990412)81:2<214::AID-IJC8>3.0.CO;2-L

Absetz, P., Aro, A. R., \& Sutton, S. R. (2003). Experience with breast cancer, pre-screening perceived susceptibility and the psychological impact of screening. Psycho-Oncology 12(4), 305-318. doi: 10.1002/pon.644

Aktan-Collan, K., Kääriäinen, H., Järvinen, H., Peltomäki, P., Pylvänäinen, K., Mecklin, J. P., \& Haukkala, A. (2013). Psychosocial consequences of predictive genetic testing for lynch syndrome and associations to surveillance behaviour in a 7-year follow-up study. Familial Cancer, 10, 1-8. doi: 10.1007/s10689.013-9628-9

Alberts, N. M., Hadjistavropoulos, H. D., Jones, S. L., \& Sharpe, D. (2013). The Short Health Anxiety Inventory: A systematic review and meta-analysis. Journal of Anxiety Disorders, 1, 68-78. doi: 10.1016/j.janxdis.2012.10.009

Alberts, N. M., Sharpe, D., Kehler, M. D., \& Hadjistavropoulos, H. D. (2011). Health anxiety: Comparison of the latent structure in medical and non-medical samples. Journal of Anxiety Disorders, 25(4), 612-614. doi: 10.1016/j.janxdis.2011.01.011

Andersen, R., \& Newman, J. F. (2005). Societal and individual determinants of medical care utilization in the United States. The Milbank Quarterly, 83, 1-28.

Andersen, R. M. (1995). Revisiting the behavioral model and access to medical care: Does it matter? Journal of Health and Social Behavior, 36(1), 1-10. 
Anderson, L. A., \& Dedrick R. F. (1990). Development of the Trust in Physician Scale: a measure to assess interpersonal trust in patient-physician relationships. Psychological Reports 67, 1091-1100.

Baider, L., \& De-Nour, A. K. (1997). Psychological distress and intrusive thoughts in cancer patients. The Journal of Nervous and Mental Disease, 185(5), 346-348.

Baker, F., Denniston, M., Smith, T., \& West, M. M. (2005). Adult cancer survivors: How are they faring? Cancer, 104(S11), 2565-2576. doi: 10.1002/cncr.21488

Bakker, D. A., Fitch, M. I., Gray, R., Reed, E., \& Bennett, J. (2001). Patient-health care provider communication during chemotherapy treatment: The perspectives of women with breast cancer. Patient Education and Counseling, 43, 61-71. doi: 10.1016/S07383991(00)00147-6

Barsky, A. J., Coeytaux, R. R., Sarnie, M. K., \& Cleary, P. D. (1993). Hypochondriacal patients' beliefs about good health. American Journal of Psychiatry, 150, 1085-1089.

Barsky, A. J., Delamater, B. A., \& Orav, J. E. (1999). Panic disorder patients and their medical care. Psychosomatics, 40(1), 50-56. doi: 10.1016/S0033-3182(99)71271-5

Barsky, A. J., Ettner, S. L., Horsky, J., \& Bates, D. W. (2001). Resource utilization of patients with hypochondriacal health anxiety and somatization. Medical Care, 39(7), 705-715.

Becker, M. H., \& Maiman, L. A. (1975). Sociobehavioral determinants of compliance with health and medical care recommendations. Medical Care, 13(1), 10-24.

Belanger L., Ladouceur R., \& Morin C. M. (2005). Generalized anxiety disorder and health care use. Canadian Family Physician, 51,1362-1363. 
Bellizzi, K. M., Latini, D. M., Cowan, J. E., DuChane, J., \& Carroll, P. R. (2008). Fear of recurrence, symptom burden, and health-related quality of life in men with prostate cancer. Urology, 72(6), 1269-1273. doi: 10.1016/j.urology.2007.12.084

Bereza, B.G., Machado, M., \& Einarson, T.R. (2009). Systemic review and quality assessment of economic evaluations and quality-of-life studies related to generalized anxiety disorder. Clinical Therapeutics, 31, 1279-1308. doi: 10.1016/j.clinthera.2009.06.004

Bernhardt, B. A., Geller, G., Strauss, M., Helzlsouer, K. J., Stefanek, M., Wilcox, P. M., \& Holtzman, N. A. (1997). Toward a model informed consent process for BRCA1 testing: A qualitative assessment of women's attitudes. Journal of Genetic Counseling, 6(2), 207222.

Bhandari, A., \& Wagner, T. (2006). Self-reported utilization of health care services: improving measurement and accuracy. Medical Care Research and Review, 63(2), 217-235. doi: $10.1177 / 1077558705285298$

Biesecker, B. B., Boehnke, M., Calzone, K., Markel, D. S., Garber, J. E., Collins, F. S., \& Weber, B. L. (1993). Genetic counseling for families with inherited susceptibility to breast and ovarian cancer. JAMA: The Journal of the American Medical Association, 269(15), 1970-1974.

Biesecker, B. B., \& Erby, L. (2008). Adaptation to living with a genetic condition or risk: A mini review. Clinical Genetics, 74, 401-407. doi: 10.1111/j.1399-0004.2008.01088.x

Bish, A., Sutton, S., Jacobs, C., Levene, S., Ramirez, A., \& Hodgson, S. (2002). No news is (not necessarily) good news: Impact of preliminary results for BRCA1 mutation searches. Genetics in Medicine, 4(5), 353-358. 
Bloom, J. R., Stewart, S. L., Johnston, M., Banks, P., \& Fobair, P. (2001). Sources of support and the physical and mental well-being of young women with breast cancer. Social Science \& Medicine, 53(11), 1513-1524. doi: 10.1016/S0277-9536(00)00440-8

Boland C. R., \& Shike, M. (2010). Report from the Jerusalem workshop on Lynch syndrome hereditary nonpolyposis colorectal cancer. Gastroenterology, 138, 2197. doi: 10.1053.j.gastro.2010.04.024

Bowen, D. J., Helmes, A., Powers, D., Andersen, M. R., Burke, W., McTiernan, A., \& Durfy, S. (2003). Predicting breast cancer screening intentions and behavior with emotion and cognition. Journal of Social Clinical Psychology, 22, 213-232.

Bowen, D. J., Hickman, K. M., \& Powers, D. (1997). Importance of psychological variables in understanding risk perception and breast cancer screening of African American women. Women's Health Research on Gender Behavior and Policy, 3, 227-242.

Braithwaite, D., Emery, J., Walter, F., Prevost, A. T., \& Sutton, S. (2006). Psychological impact of genetic counseling for familial cancer: A systematic review and meta-analysis. Familial Cancer, 5, 61-75. doi: 10.1093/jnci/djh017

Broadstock, M., Michie, S., \& Marteau, T. (2000). Psychological consequences of predictive genetic testing: A systematic review. European Journal of Human Genetics, 8, 731-738. doi:10.1038/sj.ejhg.5200532

Brown, J. B., Boles, M., Mullooly, J. P., \& Levinson, W. (1999). Effect of clinician communication skills training on patient satisfaction: A randomized, controlled trial. Annals of Internal Medicine, 131(11), 822-829. doi:10.7326/0003-4819-131-11199912070-00004 
Buhr, K., \& Dugas, M. J. (2002). The Intolerance of Uncertainty Scale: Psychometric properties of the English version. Behavior Research and Therapy, 40, 931-945. doi: 10.1016/S0005-7967(01)00092-4

Buller, M. K., \& Buller, D. B. (1987). Physicians' communication style and patient satisfaction. Journal of Health and Social Behavior, 28(4), 375-388.

Burstein, H. J., Gelber, S., Guadagnoli, E., \& Weeks, J. C. (1999). Use of alternative medicine by women with early-stage breast cancer. New England Journal of Medicine, 340, 17331739.

Butow, P. N., Lobb, E. A., Meiser, B., Barratt, A., \& Tucker, K. M. (2003). Psychological outcomes and risk perception after genetic testing and counseling in breast cancer: A systematic review. Medical Journal of Australia, 178, 77-81.

Cameron, L. D., Leventhal, E. A., Leventhal, H. (1995). Seeking medical care in response to symptoms and life stress. Psychosomatic Medicine, 57, 37-47.

Carleton, R. N., Norton, M. A. P. J., \& Asmundson, G. J. G. (2007). Fearing the unknown: A short version of the Intolerance of Uncertainty Scale. Journal of Anxiety Disorders, 21, 105-117. doi: 10.1016/j.janxdis.2006.03.014

Carleton, R. N., Collimore, K. C., \& Asmundson, G. J. (2010). “It's not just the judgements—It's that I don't know”: Intolerance of uncertainty as a predictor of social anxiety. Journal of Anxiety Disorders, 24(2), 189-195. doi: 10.1016/j.janxdis.2009.10.007

Chaliki, H., Loader, S., Levenkron, J. C., Logan-Young, W., Hall, W. J., \& Rowley, P. T. (1995). Women's receptivity to testing for a genetic susceptibility to breast cancer. American Journal of Public Health, 85(8), 1133-1135. 
Charles, C., Gafni, A., \& Whelan, T. (1999). Decision-making in the physician-patient encounter: Revisiting the shared treatment decision-making model. Social Science and Medicine, 49, 651-661. doi: 10.1016/S0277-9536(99)00145-8

Chewning, B., \& Sleath, B. (1996). Medication decision-making and management: A clientcentered model. Social Science \& Medicine, 42(3), 389-398. doi: 10.1016/02779536(95)00156-5

Claes, E., Evers-Kiebooms, G., Boogaerts, A., Decruyenaere, M., Denayer, L., \& Legius, E. (2003). Communication with close and distant relatives in the context of genetic testing for hereditary breast and ovarian cancer in cancer patients. American Journal of Medical Genetics, 116, 11-19. doi: 10.1002/ajmg.a.10868

Consedine, N. S., Magai, C., Krivoshekova, Y. S., Ryzewicz, L., \& Neugut, A. I. (2004). Fear, anxiety, worry, and breast cancer screening behavior: A critical review. Cancer Epidemiology Biomarkers \& Prevention, 13(4), 501-510.

Deacon, B., Lickel, J., \& Abramowitz, J. S. (2008). Medical utilization across the anxiety disorders. Journal of Anxiety Disorders, 22(2), 344-350. doi: 10.1016/j.janxdis.2007.03.004

De Bock, G. H., Bonnema, J., Zwaan, R. E., Van De Velde, C. J. H., Kievit, J., \& Stiggelbout, A. M. (2004). Patient's needs and preferences in routine follow-up after treatment for breast cancer. British Journal of Cancer, 90(6), 1144-1150. doi: 10.1038/sj.bjc.6601655

Del Giudice, M. E., Grunfeld, E., Harvey, B. J., Piliotis, E., \& Verma, S. (2009). Primary care physicians' views of routine follow-up care of cancer survivors. Journal of Clinical Oncology, 27(20), 3338-3345. doi: 10.1200/JCO.2008.20.4883 
Diefenbach, M. A., \& Leventhal, H. (1996). The common-sense model of illness representation: Theoretical and practical considerations. Journal of Social Distress and the Homeless, 5, 11-38.

DiLorenzo, T. A., Schnur, J., Montgomery, G. H., Erblich, J., Winkel, G., \& Bovbjerg, D. H. (2006). A model of disease-specific worry in heritable disease: the influence of family history, perceived risk and worry about other illnesses. Journal of Behavioral Medicine, 29(1), 37-49. doi: 10.1007/s10865-005-9039-y

DiMatteo, M. R., \& Lepper, H. S. (1998). Promoting adherence to courses of treatment: Mutual collaboration in the physician-patient relationship. Health Communication Research: A Guide to Developments and Directions, 94(7), 75-86.

Dugas, M. J., Freeston, M. H., \& Ladouceur, R. (1997). Intolerance of uncertainty and problem orientation in worry. Cognitive Therapy and Research, 21, 593-606.

Dugas, M. J., Gosselin, P., \& Ladouceur, R. (2001). Intolerance of uncertainty and worry: Investigating specificity in a non-clinical sample. Cognitive Therapy and Research, 25, $551-558$.

Easterling, D. V., \& Leventhal, H. (1989). Contribution of concrete cognition to emotion: Neutral symptoms as elicitors of worry about cancer. Journal of Applied Psychology, 74(5), 787.

Engel, J., Kerr, J., Schlesinger-Raab, A., Eckel, R., Sauer, H., \& Hölzel, D. (2003). Comparison of breast and rectal cancer patients' quality of life: Results of a four year prospective field study. European Journal of Cancer Care, 12(3), 215-223. doi: 10.1046/j.13652354.2003.00414.x 
Epping-Jordan, J. E., Compas, B. E., Osowiecki, D. M., Oppedisano, G., Gerhardt, C., Primo, K., \& Krag, D. N. (1999). Psychological adjustment in breast cancer: processes of emotional distress. Health Psychology, 18(4), 315.

Ernst, E., \& Cassileth, B. R. (1998). The prevalence of complementary/alternative medicine in cancer: A systematic review. Cancer, 83, 777-782. doi: 10.1002/(SICI)1097-0142

Escher, M., \& Sappino, A. P. (2000). Primary care physicians' knowledge and attitudes towards genetic testing for breast-ovarian cancer predisposition. Annals of Oncology, 11(9), 11311135.

Esplen, M. J., Madlensky, L., Aronson, M., Rothenmund, H., Gallinger, S., Butler, K., ... McLaughlin, J. (2007). Colorectal cancer survivors undergoing genetic testing for hereditary non-polyposis colorectal cancer: Motivational factors and psychosocial functioning. Clinical Genetics, 72(5), 394-401. doi: 10.1111/j.1399-0004.2007.00893.x

Esplen, M. J., Madlensky, L., Butler, K., McKinnon, W., Bapat, B., Wong, J., ... Gallinger, S. (2001). Motivations and psychosocial impact of genetic testing for HNPCC. American Journal of Medical Genetics, 103(1), 9-15. doi: 10.1002/ajmg.1493

Eton, D. T., Lepore, S. J., \& Helgeson, V. S. (2005). Psychological distress in spouses of men treated for early-stage prostate carcinoma. Cancer, 103, 2412-2418. doi: 10.1002/cncr.21092

Field, A. (2009). Discovering statistics using SPSS. London: Sage publications.

Fleissig, A., Jenkins, V., Catt, S., \& Fallowfield, L. (2006). Multidisciplinary teams in cancer care: are they effective in the UK? The Lancet Oncology, 7(11), 935-943. 
Freeston, M. H., Rhéaume, J., Letarte, H., Dugas, M. J., \& Ladouceur, R. (1994). Why do people worry? Personality and Individual Differences, 17, 791-802. doi: 10.1016/01918869(94)90048-5

Geller, G., Strauss, M., Bernhardt, B. A., \& Holtzman, N. A. (1997). “Decoding” informed consent: Insights from women regarding breast cancer susceptibility testing. Hastings Center Report, 27(2), 28-33.

Gentes, E. L., \& Ruscio, A. M. (2011). A meta-analysis of the relation of intolerance of uncertainty to symptoms of generalized anxiety disorder, major depressive disorder, and obsessive-compulsive disorder. Clinical Psychology Review, 31(6), 923-933. doi:10.1016/j.cpr.2011.05.001

Greco, V., \& Roger, D. (2003). Uncertainty, stress, and health. Personality \& Individual Differences, 34, 1057-1068. doi: 10.1016/S0191-8869(02)00091-0

Green, C. A., \& Pope, C. R. (1999). Gender, psychosocial factors and the use of medical services: A longitudinal analysis. Social Science \& Medicine, 48(10), 1363-1372. doi: org/10.1016/S0277-9536(98)00440-7

Hampel, H., Frankel, W. L., Martin, E., Arnold, M., Khanduja, K., Kuebler, P., ... de la Chapelle, A. (2008). Feasibility of screening for Lynch syndrome among patients with colorectal cancer. Journal of Clinical Oncology, 26, 5783-5788. doi:10.1200/JCO.2008.17.5950

Hayes, A. F., \& Matthes, J. (2009). Computational procedures for probing interactions in OLS and logistic regression: SPSS and SAS implementations. Behavior Research Methods, 41, 924-936. doi:10.3758/BRM.41.3.924

Hays, R. D., Wells, K. B., Sherbourne, C. D., Rogers, W., \& Spritzer, K. (1995). Functioning and well-being outcomes of patients with depression compared with chronic general 
medical illnesses. Archives of General Psychiatry, 52(1), 11.

doi:10.1001/archpsyc.1995.03950130011002

He, T. (1996). Statement of the American Society of Clinical Oncology: Genetic testing for cancer susceptibility. Journal of Clinical Oncology, 14(5), 1730-1736.

Hewitt, M., Rowland, J. H., \& Yancik, R. (2003). Cancer survivors in the United States: Age, health, and disability. Journal of Gerontology: Biological Sciences and Medical Sciences. 58, 82-91.

Hoffman, R. M., Gilliland, F. D., Eley, J. W., Harlan, L. C., Stephenson, R. A., Stanford, J. L., ... Potosky, A. L. (2001). Racial and ethnic differences in advanced-stage prostate cancer: The Prostate Cancer Outcomes Study. Journal of the National Cancer Institute, 93(5), 388-395.

Holaway, R. M., Heimberg, R. G., \& Coles, M. E. (2006). A comparison of intolerance of uncertainty in analogue obsessive-compulsive disorder and generalized anxiety disorder. Journal of Anxiety Disorders, 20(2), 158-174. doi:10.1016/j.janxdis.2005.01.002

Hong, Y. M., Hu, J. C., Paciorek, A. T., Knight, S. J., \& Carroll, P. R. (2010). Impact of radical prostatectomy positive surgical margins on fear of cancer recurrence: Results from CaPSURE. Urologic Oncology: Seminars and Original Investigations, 20 (3), 268-273.

Hoogerbrugge, N., Kamm, Y. J. L., Bult, P., Landsbergen, K. M., Bongers, E. M. H. F., Brunner, H. G., ... Boetes, C. (2008). The impact of a false-positive MRI on the choice for mastectomy in BRCA mutation carriers is limited. Annals of Oncology, 19(4), 655-659.

Hopwood, P., Keeling, F., Long, A., Pool, C., Evans, G., \& Howell, A. (1998). Psychological support needs for women at high genetic risk of breast cancer: Some preliminary 
indicators. Psycho-Oncology, 7(5), 402-412. doi: 10.1002/(SICI)1099-

1611(1998090)7:5<402::AID-PON317>3.0.CO;2-X

Howlader, N., Noone, A. M., Krapcho, M., Garshell, J., Neyman, N., Altekruse, S. F., ... Cronin, K.A. (eds) (2013). SEER Cancer Statistics Review, 1975-2010, National Cancer Institute. Bethesda, MD, http://seer.cancer.gov/csr/1975_2010/, based on November 2012 SEER data submission, posted to the SEER web site.

Hitchcock, P. B., \& Mathews, A. (1992). Interpretation of bodily symptoms in hypochondriasis. Behaviour Research and Therapy, 30, 223-234. doi: 10.1016/0005-7967(92)90068-R

Jenkins, M. A., Baglietto, L., Dowty, J. G., Van Vliet, C. M., Smith, L., Mead, L. J., ... Southey, M. C. (2006). Cancer risks for mismatch repair gene mutation carriers: A populationbased early onset case-family study. Clinical Gastroenterology and Hepatology, 4(4), 489-498. doi: 10.1016/j.cgh.2006.01.002

Kash, K. M., Holland, J. C., Halper M. S., \& Miller, D. G. (1992). Psychological distress and surveillance behaviors of women with a family history of breast cancer. Journal of the National Cancer Institute, 84, 24-30.

Kasparian, N. A., Meiser, B., Butow, P. N., Simpson, J. M., \& Mann, G. J. (2008). Predictors of psychological distress among individuals with a strong family history of malignant melanoma. Clinical Genetics, 73(2), 121-131.

Kehler, M., \& Hadjistavropoulos, H. (2009). Is health anxiety a significant problem for individuals with multiple sclerosis? Journal of Behavioral Medicine, 32(2), 150-161. doi:10.1007/s10865-008-9186-z.

Keller, M., Jost, R., Haunstetter, C. M., Sattel, H., Schroeter, C., Bertsch, U., ... Brechtel, A. (2008). Psychosocial outcome following genetic risk counseling for familial colorectal 
cancer. A comparison of affected patients and family members. Clinical Genetics, 74(5), 414-424. doi: 10.1111/j.1399-0004.2008.01089.x

Kennedy, B. L., \& Schwab, J. J. (1997). Utilization of medical specialists by anxiety disorder patients. Psychosomatics, 38(2), 109-112. doi: 10.1016/S0033-3182(97)71478-6

Kerr, J., Engel, J., Schlesinger-Raab, A., Sauer, H., \& Hölzel, D. (2003). Communication, quality of life and age: Results of a 5-year prospective study in breast cancer patients. Annals of Oncology, 14(3), 421-427. doi: 10.1093/annonc/mdg098

Kurita, K., Garon, E. B., Stanton, A. L., \& Meyerowitz, B. E. (2012). Uncertainty and psychological adjustment in patients with lung cancer. Psycho-Oncology, 22(6), 13961401. doi: 10.1002/pon.3155

Ladouceur, R., Gosselin, P., \& Dugas, M. J. (2000). Experimental manipulation of intolerance of uncertainty: A study of a theoretical model of worry. Behaviour Research and Therapy, 38, 933-941. doi: 10.1016/S0005-7967(99)00133-3

Lafferty, W. E., Tyree, P. T., Bellas, A. S., Watts, C. A., Lind, B. K., Sherman, K. J., ... Grembowski, D. E. (2006). Insurance coverage and subsequent utilization of Complementary and Alternative Medical (CAM) providers. The American Journal of Managed Care, 12(7), 397.

Lancaster, J. M., Carney, M. E., \& Futreal, P. A. (1997). BRCA 1 and 2--A genetic link to familial breast and ovarian cancer. Medscape Women's Health, 2(2), 7-7.

Landsbergen, K. M., Prins, J. B., Brunner, H. G., van Duijvendijk, P., Nagengast, F. M., van Krieken, J. H., ... \& Hoogerbrugge, N. (2012). Psychological distress in newly diagnosed colorectal cancer patients following microsatellite instability testing for Lynch syndrome on the pathologist's initiative. Familial Cancer, 11(2), 259-267. 
Lazarus, R.S., \& Folkman, S. (1984). Stress, Appraisal, and Coping. Springer: New York.

Lebel, S., Rosberger, Z., Edgar, L., \& Devins, G. M. (2007). Comparison of four common stressors across the breast cancer trajectory. Journal of Psychosomatic Research, 63(3), 225-232.

Lee, J. K., Orsillo, S. M., Roemer, L., \& Allen, L. B. (2010). Distress and avoidance in generalized anxiety disorder: Exploring the relationships with intolerance of uncertainty and worry. Cognitive Behaviour Therapy, 39(2), 126-136. doi: 0.1080/16506070902966918

Lee-Jones, C., Humphris, G., Dixon, R., \& Bebbington Hatcher, M. (1997). Fear of cancer recurrence: A literature review and proposed cognitive formulation to explain exacerbation of recurrence fears. Psycho-Oncology, 6(2), 95-105.

Lekander, M., Furst, C.J., Rotstein, S., Blomgren, H., \& Fredrikson, M. (1996). Social support and immune status during and after chemotherapy for breast cancer. Acta Oncologica, 35, 31-37. doi: 10.3109/02841869609098476

Lerman, C., Daly, M., Masny, A., \& Balshem, A. (1994). Attitudes about genetic testing for breast-ovarian cancer susceptibility. Journal of Clinical Oncology, 12(4), 843-850.

Lerman, C., \& Shields, A. E. (2004). Genetic testing for cancer susceptibility: The promise and the pitfalls. Nature Reviews Cancer, 4(3), 235-241.

Leventhal, H., Meyer, D., \& Nerenz, D. (1980). The common sense representation of illness danger. Contributions to Medical Psychology, 2, 7-30.

Lindor, N. M., Petersen, G. M., Hadley, D. W., Kinney, A. Y., Miesfeldt, S., Lu, K. H., ... Press, N. (2006). Recommendations for the care of individuals with an inherited predisposition 
to Lynch syndrome. JAMA: The Journal of the American Medical Association, 296, 1507 -1517. doi:10.1001/jama.296.12.1507

Llewellyn, C. D., Weinman, J., McGurk, M., \& Humphris, G. (2008). Can we predict which head and neck cancer survivors develop fears of recurrence? Journal of Psychosomatic Research, 65(6), 525-532. doi: 10.1016/j.jpsychores.2008.03.014

Lloyd, S., Watson, M., Waites, B., Meyer, L., Eeles, R., Ebbs, S., \& Tylee, A. (1996). Familial breast cancer: A controlled study of risk perception, psychological morbidity and health beliefs in women attending for genetic counseling. British Journal of Cancer, 74, 482487. doi:10.1038/bjc.1996.387

Lorig, K. R., Ritter, P., Stewart, A. L., Sobel, D. S., Brown Jr, B. W., Bandura, A., ... Holman, H. R. (2001). Chronic disease self-management program: 2-year health status and health care utilization outcomes. Medical Care, 39(11), 1217-1223.

Lynch, H. T., \& de la Chapelle, A. (2003). Genomic medicine: Hereditary colorectal cancer. New England Journal of Medicine, 348, 919-932.

Maissi, E., Marteau, T. M., Hankins, M., Moss, S., Legood, R., \& Gray, A. (2004).

Psychological impact of human papillomavirus testing in women with borderline or mildly dyskaryotic cervical cancer smear results: Cross sectional questionnaire study. British Medical Journal, 328, 1-6.

Marciniak, M. D., Lage, M. J., Dunayevich, E., Russell, J. M., Bowman, L., Landbloom, R. P., \& Levine, L. R. (2005). The cost of treating anxiety: The medical and demographic correlates that impact total medical costs. Depression and Anxiety, 21(4), 178-184. doi: 10.1002/da.20074 
Marcus, D. K. (1999). The cognitive-behavioral model of hypochondriasis: Misinformation and triggers. Journal of Psychosomatic Research, 47, 79-91. doi: 10.1016/S00223999(99)00008-2

McWilliam, C. L., Brown, J. B., \& Stewart, M. (2000). Breast cancer patients’ experiences of patient-doctor communication: A working relationship. Patient Education and Counseling, 39, 191-204. doi: 10.1016/S0738-3991(99)00040-3

Mishel, M. H. (1981). The measurement of uncertainty in illness. Nursing Research, 30(5), 258263.

Mishel, M. H., Germino, B. B., Gil, K. M., Belyea, M., LaNey, I. C., Stewart, J., ... Clayton, M. (2005). Benefits from an uncertainty management intervention for African-American and Caucasian older long-term breast cancer survivors. Psycho-Oncology, 14(11), 962-978. doi: 10.1002/pon.909

Murday, V. (1994). Genetic counselling in the cancer family clinic. European Journal of Cancer, 30(13), 2012-2015.

Nakao, M., Shinozaki, Y., Ahern, D. K., \& Barsky, A. J. (2011). Anxiety as a predictor of improvements in somatic symptoms and health anxiety associated with cognitivebehavioral intervention in hypochondriasis. Psychotherapy and Psychosomatics, 80(3), 151-158.

Olfson, M., \& Gameroff, M.J. (2007). Generalized anxiety disorder, somatic pain and health care costs. General Hospital Psychiatry, 29, 310-316. doi:

10.1016/j.genhosppsych.2007.04.004

O'Neill, S. C., DeMarco, T., Peshkin, B. N., Rogers, S., Rispoli, J., Brown, K., ... Schwartz, M. D. (2006). Tolerance for uncertainty and perceived risk among women receiving 
uninformative BRCA1/2 test results. American Journal of Medical Genetic, 251-259. doi: 10.1002/ajmg.c.30104

Padilla, G. V., Mishel, M. H., \& Grant, M. M. (1992). Uncertainty, appraisal and quality of life. Quality of Life Research, 1(3), 155-165.

Reichelt, J. G., Heimdal, K., Møller, P., \& Dahl, A. A. (2004). BRCA1 testing with definitive results: A prospective study of psychological distress in a large clinic-based sample. Familial Cancer, 3(1), 21-28.

Renton, J. P., Twelves, C. J., \& Yuille, F. A. P. (2002). Follow-up in women with breast cancer: The patients' perspective. The Breast, 11(3), 257-261. doi: 10.1054/brst.2002.0411

Richards, M. A., Ramirez, A. J., Degner, L. F., Fallowfield, L. J., Maher, E. J., \& Neuberger, J. (1995). Offering choice of treatment to patients with cancers: A review based on a symposium held at the 10th annual conference of The British Psychosocial Oncology Group, December 1993. European Journal of Cancer, 31A, 112-116. doi: 10.1016/09598049(94)00478-N

Richardson, M. A., Sanders, T., Palmer, J. L., Greisinger, A., \& Singletary, S. E. (2000). Complementary/alternative medicine use in a comprehensive cancer center and the implications for oncology. Journal of Clinical Oncology, 18, 2505-2514.

Rimes, K. A., Salkovskis, P. M., Jones, L., \& Lucassen, A. M. (2006). Applying a cognitive behavioral model of health anxiety in a cancer genetics service. Health Psychology, 25, 171-180. doi:10.1037/0278-6133.25.2.171

Ritter, P. L., Stewart, A. L., Kaymaz, H., Sobel, D. S., Block, D. A., \& Lorig, K. R. (2001). Selfreports of health care utilization compared to provider records. Journal of Clinical Epidemiology, 54(2), 136-141. doi: 10.1016/S0895-4356(00)00261-4 
Ritvo, P., Robinson, G., Irvine, J., Brown, L., Murphy, K. J., Stewart, D. S., ... Rosen, B. (1999). A longitudinal study of psychological adjustment to familial genetic risk assessment for ovarian cancer. Gynecologic Oncology, 74(3), 331-37. doi: 10.1006/gyno.1999.5518

Robinson, J. R., Young, T. K., Roos, L. L., \& Gelskey, D. E. (1997). Estimating the burden of disease: Comparing administrative data and self-reports. Medical Care, 35(9), 932-947.

Roorda, C., Berendsen, A. J., Groenhof, F., van der Meer, K., \& de Bock, G. H. (2012). Increased primary healthcare utilization among women with a history of breast cancer. Supportive Care in Cancer, 21(4), 441-449. doi: 10.1007/s00520-012-1609-2

Rose, J. H. (1990). Social support and cancer: Adult patients’ desire for support from family, friends, and health professionals. American Journal of Community Psychology, 18, 439464. doi: 10.1007/BF00938117

Rosen, N. O., Knäuper, B., \& Sammut, J. (2007). Do individual differences in intolerance of uncertainty affect health monitoring? Psychology and Health, 22(4), 413-430.

Schain, W. S. (1990). Physician-patient communication about breast cancer: A challenge for the 1990s. Surgical Clinics of North America, 70, 917-935.

Schnur, J. B., DiLorenzo, T. A., Montgomery, G. H., Erblich, J., Winkel, G., Hall, S. J., \& Bovbjerg, D. H. (2006). Perceived risk and worry about prostate cancer: A proposed conceptual model. Behavioral Medicine, 32(3), 89-96.

Schofield, P. E., Butow, P. N., Thompson, J. F., Tattersall, M. H. N., Beeney, L. J., \& Dunn, S. M. (2003). Psychological responses of patients receiving a diagnosis of cancer. Annals of Oncology, 14(1), 48-56. doi: 10.1093/annonc/mdg010 
Schwartz, M., Lerman, C., Daly, M., Audrain, J., Masny, A., \& Griffith K. (1995). Utilization of ovarian cancer screening by women testing at increased risk. Cancer Epidemiology Biomarkers Prevention, 4, 269-73.

Shiloh, S., Drori, E., Orr-Urtreger, A., \& Friedman, E. (2009). Being ‘at-risk’ for developing cancer: Cognitive representations and psychological outcomes. Journal of Behavioral Medicine, 32(2), 197-208.

Simard, S., \& Savard, J. (2009). Fear of Cancer Recurrence Inventory: Development and initial validation of a multidimensional measure of fear of cancer recurrence. Supportive Care in Cancer, 17(3), 241-251. doi: 10.1007/s00520-008-0444-y

Spiegel, T. N., Esplen, M. J., Hill, K. A., Wong, J., Causer, P. A., \& Warner, E. (2011).

Psychological impact of recall on women with BRCA mutations undergoing MRI surveillance. The Breast, 20(5), 424-430. doi: 10.1016/j.breast.2011.04.004

Stafford, R. S. \& Cyr, P. L. (1997). The impact of cancer on the physical function of the elderly and their utilization of health care. Cancer, 80, 1973-1980. doi: 10.1002/(SICI)10970142(19971115)80:10<1973::AID-CNCR15>3.0.CO;2

Stanton, A. L., Danoff-Burg, S., Sworowski, L. A., Collins, C. A., Branstetter, A. D., RodriguezHanley, A., ... Austenfeld, J. L. (2002). Randomized, controlled trial of written emotional expression and benefit finding in breast cancer patients. Journal of Clinical Oncology, 20(20), 4160-4168.

Stewart, M. A. (1995). Effective physician-patient communication and health outcomes: A review. Canadian Medical Association Journal, 152, 1423-1433.

Takayama, T., Yamazaki, Y., \& Katsumata, N. (2001). Relationship between outpatients’ perceptions of physicians’ communication styles and patients’ anxiety levels in a 
Japanese oncology setting. Social Science \& Medicine, 53, 1335-1350. doi:

10.1016/S0277-9536(00)00413-5

Tambor, E. S., Rimer, B. K., \& Strigo, T. S. (1997). Genetic testing for breast cancer susceptibility: Awareness and interest among women in the general population. American Journal of Medical Genetics, 68(1), 43-49. doi: 10.1002/(SICI)10968628(19970110)68:1<43::AID-AJMG8>3.0.CO;2-Z

Tang, N. K., Wright, K. J., \& Salkovskis, P. M. (2007). Prevalence and correlates of clinical insomnia co-occurring with chronic back pain. Journal of Sleep Research, 16(1), 85-95.

Thom, D. H., \& Campbell B. (1997). Patient-physician trust: An exploratory study. Journal of Family Practice, 44, 169-176.

Trask, P. C., Paterson, A. G., Wang, C., Hayasaka, S., Milliron, K. J., Blumberg, L. R., ... Merajver, S. D. (2001). Cancer-specific worry interference in women attending a breast and ovarian cancer risk evaluation program: Impact on emotional distress and health functioning. Psycho-Oncology, 10, 349-360. doi:10.1002/pon.510

Trummer, U. F., Mueller, U. O., Nowak, P., Stidl, T., \& Pelikan, J. M. (2006). Does physicianpatient communication that aims at empowering patients improve clinical outcome? A case study. Patient Education and Counseling, 61, 299-306.

van Dooren, S., Rijnsburger, A. J., Seynaeve, C., Duivenvoorden, H.J., Essink-Bot, M. L., Tilanus-Linthorst, M. M., ... Tibben, A. (2004). Psychological distress in women at increased risk for breast cancer: The role of risk perception. European Journal of Cancer, 40, 2056-2063.

van Hezewijk, M., Ranke, G. M., van Nes, J. G., Stiggelbout, A. M., de Bock, G. H., \& van de Velde, C. J. (2011). Patients' needs and preferences in routine follow-up for early breast 
cancer: An evaluation of the changing role of the nurse practitioner. European Journal of Surgical Oncology (EJSO), 37(9), 765-773. doi: 10.1016/j.ejso.2011.06.007

van Oostrom, I., Meijers-Heijboer, H., Duivenvoorden, H. J., Bröcker-Vriends, A. H., van Asperen, C. J., Sijmons, R. H., ... Tibben, A. (2007). Comparison of individuals opting for BRCA1/2 or HNPCC genetic susceptibility testing with regard to coping, illness perceptions, illness experiences, family system characteristics and hereditary cancer distress. Patient Education and Counseling, 65, 58-68. doi: 10.1016/j.pec.2006.05.006 Van Roosmalen, M. S., Stalmeier, P. F. M., Verhoef, L. C. G., Hoekstra-Weebers, J. E. H. M., Oosterwijk, J. C., Hoogerbrugge, N., ... van Daal, W. A. J. (2004). Randomized trial of a shared decision-making intervention consisting of trade-offs and individualized treatment information for BRCA1/2 mutation carriers. Journal of Clinical Oncology, 22(16), 32933301. doi: 10.1200/JCO.2004.05.066

Vos, J., Menko, F. H., Oosterwijk, J. C., Asperen, C. J., Stiggelbout, A. M., \& Tibben, A. (2012). Genetic counseling does not fulfill the counselees' need for certainty in hereditary breast/ovarian cancer families: An explorative assessment. Psycho-Oncology, 22(5), 1167-1176.

Warwick, H. M. C., \& Salkovskis, P. M. (1990). Hypochondriasis. Behaviour Research and Therapy, 28, 105-117. doi:10.1016/0005-7967(90)90023-C

Watson, M., Lloyd, S., Davidson, J., Meyer, L., Eeles, R., Ebbs, S., \& Murday, V. (1999). The impact of genetic counselling on risk perception and mental health in women with a family history of breast cancer. British Journal of Cancer, 79, 868-874.

Watson, P. \& Riley, B. (2005). The tumor spectrum in the Lynch syndrome. Familial Cancer, 4, 245-248. 
Weinstein, N. D., \& Klein, W. M. (1995). Resistance of personal risk perceptions to de-biasing interventions. Health Psychology, 14, 132-140. doi: 10.2337/diacare.26.9.2543

Wellisch, D. K., Gritz, E. R., Schain, W., Wang, H. J., \& Siau, J. (1991). Psychological functioning of daughters of breast cancer patients: Part I: Daughters and comparison subjects. Psychosomatics, 32(3), 324-336.

Wellisch, D. K., Gritz, E. R., Schain, W., Wang, H. J., \& Siau, J. (1992). Psychological functioning of daughters of breast cancer patients: Part II: Characterizing the distressed daughter of the breast cancer patient. Psychosomatics, 33(2), 171-179.

Yook, K., Kim, K. H., Suh, S. Y., \& Lee, K. S. (2010). Intolerance of uncertainty, worry, and rumination in major depressive disorder and generalized anxiety disorder. Journal of Anxiety Disorders, 24(6), 623-628. doi: 10.1016/j.janxdis.2010.04.003

Zakowski, S. G., Valdimarsdottir, H. B., Bovbjerg, D. H., Borgen, P., Holland, J., Kash, K., ... Van Zee, K. (1997). Predictors of intrusive thoughts and avoidance in women with family histories of breast cancer. Annals of Behavioral Medicine, 19(4), 362-369.

Zane, R. D., McAfee, A. T., Sherburne, S., Billeter, G., \& Barsky, A. (2003). Panic disorder and emergency services utilization. Academic Emergency Medicine, 10(10), 1065-1069. doi:10.1197/S1069-6563(03)00349-X 
Table 1.

Sample demographics $(N=128)$

Variable

Age (years)

Time Since Lynch syndrome Diagnosis

(years)

Time Since First Cancer Diagnosis

(years)

Ethnicity

White

Asian

Black

Aboriginal

Other

Employment status

Employed (Full or part-time)

Retired

Disability

Unemployed

Average Annual Income

$$
\begin{aligned}
& 0-40,000 \\
& 40,000-75,000
\end{aligned}
$$

4.76 (3.98)

15.44

52.53 (14.49)

23-86

16.19 (11.98)

64.00
Range

$116(90.6)$

$6(4.7)$

2 (1.6)

$1(0.8)$

2 (1.6)

$77(60.2)$

31 (24.2)

3 (2.3)

15 (11.7)

53 (41.4)

30 (23.4) 
$>75,000$

Education

High school or below

Some college/University

College/University Degree

Graduate Degree

Relationship Status

Married/partnered

Single

Widowed

Divorced/Separated
31 (24.2)

28 (21.9)

29 (22.7)

49 (38.3)

20 (15.6)

102 (79.7)

$11(8.6)$

7 (5.5)

6 (4.7) 
Table 2.

Cancer diagnoses $(N=128)$

\begin{tabular}{|c|c|c|c|c|c|c|}
\hline Type of Cancer & $\begin{array}{c}1^{\text {st }} \\
\text { Cancer } \\
n(\%) \\
\end{array}$ & $\begin{array}{c}2^{\text {nd }} \\
\text { Cancer } \\
n(\%) \\
\end{array}$ & $\begin{array}{c}3^{\text {rd }} \\
\text { Cancer } \\
n(\%) \\
\end{array}$ & $\begin{array}{c}4^{\text {th }} \\
\text { Cancer } \\
n(\%) \\
\end{array}$ & $\begin{array}{c}5^{\text {th }} \\
\text { Cancer } \\
n(\%) \\
\end{array}$ & $\begin{array}{l}\text { TOTAL } \\
n(\%)\end{array}$ \\
\hline Colorectal & $41(31.4)$ & $13(41.8)$ & $5(4.0)$ & $2(1.6)$ & $3(2.3)$ & $64(81.1)$ \\
\hline Endometrial/uterine & $26(20.3)$ & 17 (13.3) & $4(3.1)$ & $1(0.8)$ & 0 & $48(37.5)$ \\
\hline Ovarian & $3(2.3)$ & $4(3.1)$ & $2(1.6)$ & 0 & $1(0.8)$ & $10(7.8)$ \\
\hline Breast & $4(3.1)$ & $4(3.1)$ & $4(3.1)$ & 0 & $3(2.3)$ & 15 (11.6) \\
\hline Bladder & $1(0.8)$ & 0 & 0 & $2(1.6)$ & 0 & $3(2.4)$ \\
\hline Cervical & $4(3.1)$ & 0 & $1(0.8)$ & 0 & 0 & $5(3.9)$ \\
\hline Ureter & 0 & $2(1.6)$ & 0 & 0 & 0 & $2(1.6)$ \\
\hline Kidney & 0 & 0 & $2(1.6)$ & $1(0.8)$ & 0 & $3(2.4)$ \\
\hline Stomach & 0 & 0 & $1(0.8)$ & 0 & 0 & $1(0.8)$ \\
\hline Spine & 0 & 0 & 0 & $1(0.8)$ & 0 & $1(0.8)$ \\
\hline Sarcoma & 0 & 0 & 0 & $1(0.8)$ & 0 & $1(0.8)$ \\
\hline Hepatobiliary & 0 & 0 & 0 & $1(0.8)$ & 0 & $1(0.8)$ \\
\hline Fallopian Tube & 0 & 0 & 0 & 0 & 0 & 0 \\
\hline Unspecified & 0 & 0 & 0 & $1(0.8)$ & 0 & $1(0.8)$ \\
\hline Total n (\%) & $79(62.0)$ & 40 (62.9) & $19(15.0)$ & $10(8.0)$ & $7(5.4)$ & \\
\hline
\end{tabular}


Table 3.

Regression results for association of intolerance of uncertainty and the outcome cancer-specific worry interference.

\begin{tabular}{lcccc}
\hline Variable & \multicolumn{2}{c}{ Block 1 } & \multicolumn{2}{c}{ Block 2 } \\
\cline { 2 - 5 } Age & B & SE B & SE B \\
Education & -.129 & .023 & -.043 & .022 \\
Number of first degree relatives & -.080 & .262 & .110 & .302 \\
diagnosed with Lynch & .103 & .324 & -.074 & .244 \\
Number of all relatives diagnosed & .022 & .036 & .075 & .033 \\
with cancer & & & $.381 * *$ & .433 \\
Intolerance of uncertainty & & & & \\
$R^{2}$ & & .043 & & .177 \\
$R^{2}$ adj & & .008 & & .140 \\
$R^{2}$ change & & .043 & & \\
\hline$* * p<.01$. & & & & \\
\hline
\end{tabular}


Table 4.

Regression results for association of intolerance of uncertainty and the outcome medical service utilization.

\begin{tabular}{|c|c|c|c|c|}
\hline \multirow[t]{2}{*}{ Variable } & \multicolumn{2}{|c|}{ Block 1} & \multicolumn{2}{|c|}{ Block 2} \\
\hline & $\mathrm{B}$ & SE B & $\beta$ & SE B \\
\hline Age & -.013 & .022 & -.002 & .022 \\
\hline Education & -.013 & .312 & -.011 & .313 \\
\hline $\begin{array}{l}\text { Number of first degree relatives } \\
\text { diagnosed with Lynch }\end{array}$ & .038 & .247 & .041 & .244 \\
\hline $\begin{array}{l}\text { Number of all relatives diagnosed } \\
\text { with cancer }\end{array}$ & $-.218^{*}$ & .034 & $-.208 *$ & .033 \\
\hline Intolerance of uncertainty & & & .063 & .449 \\
\hline$R^{2}$ & & .046 & & .050 \\
\hline$R^{2}$ adj & & .007 & & .001 \\
\hline$R^{2}$ change & & .046 & & .004 \\
\hline
\end{tabular}

${ }^{*} p<.05$ 
Table 5 .

Regression results for association of number of times diagnosed with cancer and the outcome cancer-specific worry interference.

\begin{tabular}{|c|c|c|c|c|}
\hline \multirow[t]{2}{*}{ Variable } & \multicolumn{2}{|c|}{ Block 1} & \multicolumn{2}{|c|}{ Block 2} \\
\hline & $\mathrm{B}$ & SE B & $\beta$ & SE B \\
\hline Age & -.117 & .023 & $-.342 *$ & .027 \\
\hline Education & .069 & .335 & .108 & .321 \\
\hline $\begin{array}{l}\text { Number of first degree relatives } \\
\text { diagnosed with Lynch }\end{array}$ & -.128 & .268 & -.098 & .257 \\
\hline $\begin{array}{l}\text { Number of all relatives diagnosed } \\
\text { with cancer }\end{array}$ & .104 & .036 & .134 & .034 \\
\hline $\begin{array}{l}\text { Number of times diagnosed with } \\
\text { cancer }\end{array}$ & & & $.390 * *$ & .285 \\
\hline$R^{2}$ & & .047 & & .143 \\
\hline$R^{2}$ adj & & .013 & & .105 \\
\hline$R^{2}$ change & & .047 & & .097 \\
\hline
\end{tabular}


Table 6.

Regression results for association of number of times diagnosed with cancer and the outcome medical service utilization.

\begin{tabular}{|c|c|c|c|c|}
\hline \multirow[t]{2}{*}{ Variable } & \multicolumn{2}{|c|}{ Block 1} & \multicolumn{2}{|c|}{ Block 2} \\
\hline & $\mathrm{B}$ & SE B & $\beta$ & $S E \mathrm{~B}$ \\
\hline Age & -.117 & .023 & $-.342 *$ & .027 \\
\hline Education & .069 & .335 & .108 & .321 \\
\hline $\begin{array}{l}\text { Number of first degree relatives } \\
\text { diagnosed with Lynch }\end{array}$ & -.128 & .268 & -.098 & .257 \\
\hline $\begin{array}{l}\text { Number of all relatives diagnosed } \\
\text { with cancer }\end{array}$ & .104 & .036 & .134 & .034 \\
\hline $\begin{array}{l}\text { Number of times diagnosed with } \\
\text { cancer }\end{array}$ & & & $.390 * *$ & .285 \\
\hline$R^{2}$ & & .047 & & .143 \\
\hline$R^{2}$ adj & & .013 & & .105 \\
\hline$R^{2}$ change & & .047 & & .097 \\
\hline
\end{tabular}


Table 7.

Moderation analyses predicting worry interference by intolerance of uncertainty and trust in physician, controlled for age, education, first degree relatives diagnosed with LS and all relatives diagnosed with cancer

\begin{tabular}{|c|c|c|c|c|}
\hline & B & $\mathrm{SE}$ & $t$ & $P$ \\
\hline Age & -.005 & .023 & -0.22 & .827 \\
\hline Education & .435 & .314 & 1.39 & .169 \\
\hline $\begin{array}{l}\text { First-degree relatives diagnosed } \\
\text { with LS }\end{array}$ & -.240 & .249 & -0.97 & .337 \\
\hline $\begin{array}{l}\text { All relatives diagnosed with } \\
\text { cancer }\end{array}$ & .036 & .035 & 1.01 & .313 \\
\hline Intolerance of uncertainty ${ }^{\mathrm{a}}$ & 1.592 & .447 & 3.56 & $.001 * *$ \\
\hline Trust in physician ${ }^{\mathrm{b}}$ & -.097 & .549 & -0.18 & .860 \\
\hline $\begin{array}{l}\text { Intolerance of uncertainty X Trust } \\
\text { in physicianc }\end{array}$ & -1.386 & .611 & -2.27 & $.025 *$ \\
\hline $\begin{array}{l}\text { IUS total }^{\mathrm{a}} \\
\text { TPS total }^{\mathrm{b}} \\
\text { IUS total } x \text { TPS total }^{\mathrm{c}} \\
* * p<.01 . \\
R^{2}=.237\end{array}$ & & & & \\
\hline
\end{tabular}


Table 8.

Moderation analyses predicting medical utilization by intolerance of uncertainty and trust in physician, controlled for age, education, first degree relatives diagnosed with LS and all relatives diagnosed with cancer

\begin{tabular}{|c|c|c|c|c|}
\hline & $\mathrm{B}$ & $\mathrm{SE}$ & $t$ & $P$ \\
\hline Age & -.005 & .025 & -0.18 & .858 \\
\hline Education & -.081 & .343 & -0.24 & .814 \\
\hline $\begin{array}{l}\text { First-degree relatives diagnosed } \\
\text { with LS }\end{array}$ & .101 & .267 & 0.38 & .706 \\
\hline All relatives diagnosed with cancer & -.063 & .038 & -1.65 & .103 \\
\hline Intolerance of uncertainty ${ }^{\mathrm{a}}$ & .468 & .495 & 0.95 & .346 \\
\hline Trust in physician ${ }^{\mathrm{b}}$ & .019 & .627 & 0.03 & .976 \\
\hline $\begin{array}{l}\text { Intolerance of uncertainty X Trust } \\
\text { in physician }{ }^{c}\end{array}$ & .927 & .655 & 1.42 & .161 \\
\hline $\begin{array}{l}\text { IUS total }^{\mathrm{a}} \\
\text { TPS total }^{\mathrm{b}} \\
\text { IUS total x TPS } \text { total }^{\mathrm{c}} \\
R^{2}=.060\end{array}$ & & & & \\
\hline
\end{tabular}


Table 9.

Moderation analyses predicting worry interference by prior cancer diagnoses and trust in physician, controlled for age, education, first degree relatives diagnosed with LS and all relatives diagnosed with cancer

\begin{tabular}{lllll}
\hline & B & SE & $t$ & $P$ \\
\hline Age & -.071 & .023 & -2.48 & .015 \\
Education & .469 & .332 & 1.42 & .160 \\
$\begin{array}{l}\text { First-degree relatives diagnosed } \\
\text { with LS }\end{array}$ & -.209 & .265 & -.79 & .431 \\
$\begin{array}{l}\text { All relatives diagnosed with cancer } \\
\text { Prior cancer diagnoses }\end{array}$ & .023 & .037 & .62 & .536 \\
$\begin{array}{l}\text { Trust in physician } \\
\text { b }\end{array}$ & .904 & .293 & 3.08 & .003 \\
$\begin{array}{l}\text { Prior cancer diagnoses X Trust in } \\
\text { physician }\end{array}$ & -.568 & .561 & -1.01 & .314 \\
\hline
\end{tabular}

Number of prior cancer diagnoses ${ }^{\mathrm{a}}$

TPS total ${ }^{\mathrm{b}}$

Number of prior cancer diagnoses X TPS total ${ }^{\mathrm{C}}$

$R^{2}=.153$ 
Table 10.

Moderation analyses predicting medical utilization by prior cancer diagnoses and trust in physician, controlled for age, education, first degree relatives diagnosed with LS and all relatives diagnosed with cancer

\begin{tabular}{lcccc}
\hline & B & SE & $t$ & $P$ \\
\hline Age & -.069 & .028 & -2.45 & .016 \\
Education & -.003 & .321 & -.01 & .992 \\
$\begin{array}{l}\text { First-degree relatives diagnosed } \\
\text { with LS }\end{array}$ & .221 & .255 & .86 & .390 \\
$\begin{array}{l}\text { All relatives diagnosed with cancer } \\
\text { Prior cancer diagnoses }\end{array}$ & -.048 & .036 & 1.35 & .181 \\
$\begin{array}{l}\text { Trust in physician } \\
\text { b }\end{array}$ & 1.045 & .282 & 3.71 & $.000 * *$ \\
$\begin{array}{l}\text { Prior cancer diagnoses X Trust in } \\
\text { physician }\end{array}$ & .176 & .587 & .30 & .765 \\
\hline
\end{tabular}

Number of prior cancer diagnoses ${ }^{\mathrm{a}}$

TPS total

Number of prior cancer diagnoses X TPS total ${ }^{\mathrm{C}}$

$* * p<.01$.

$R^{2}=.176$ 


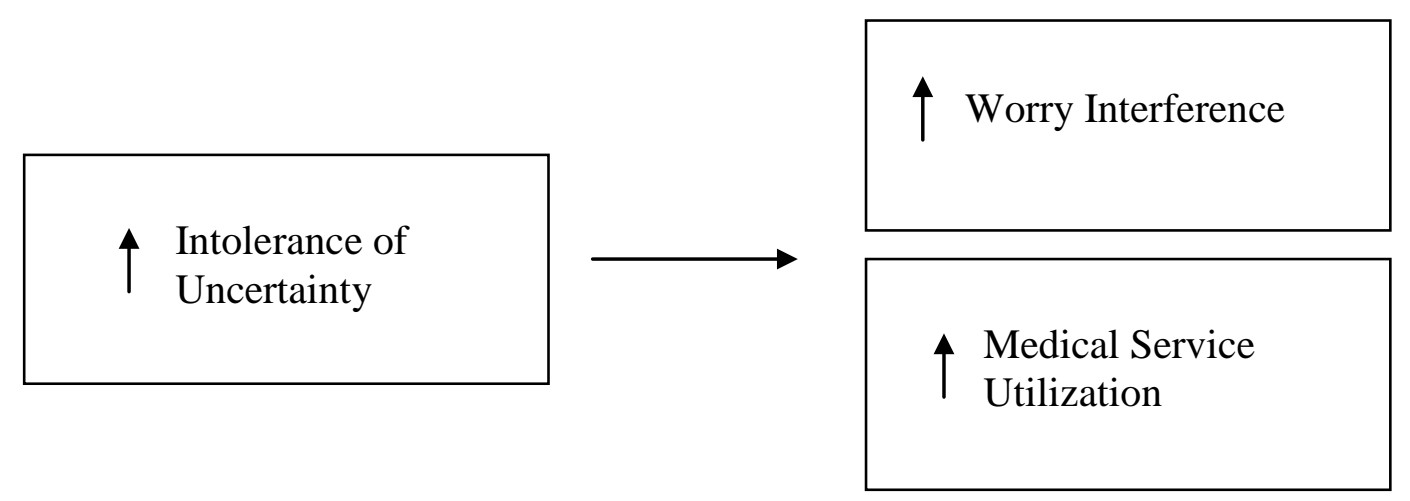

Figure 1. Aim 1: Hypothesized relationship of intolerance of uncertainty with worry interference and medical service utilization.

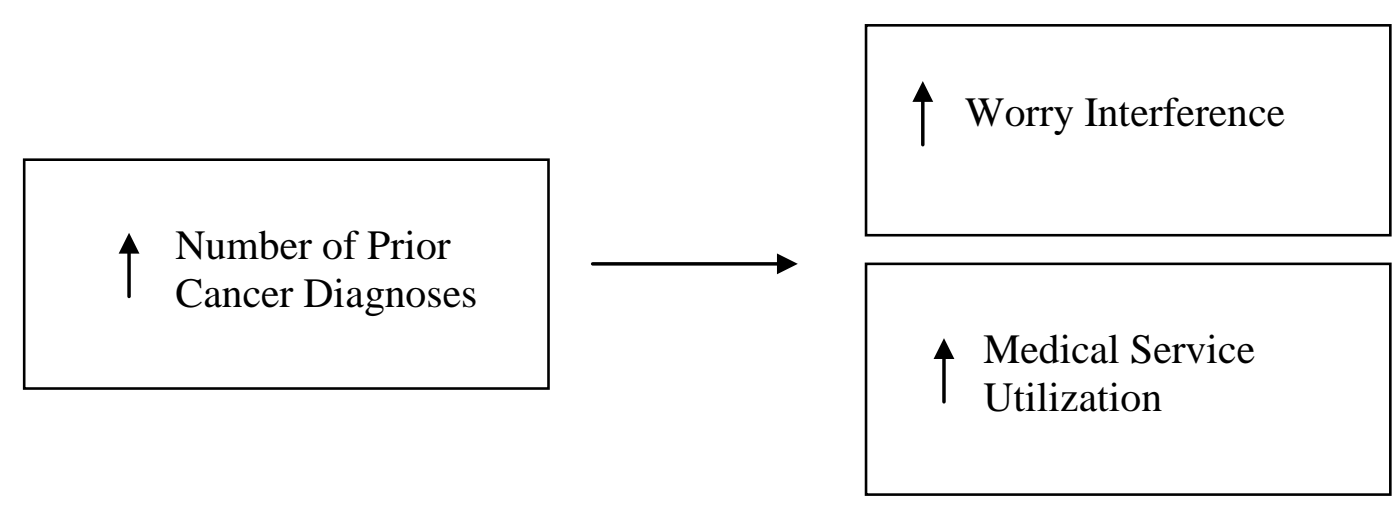

Figure 2. Aim 2: Hypothesized relationship of number of prior cancer diagnoses with worry interference and medical service utilization. 

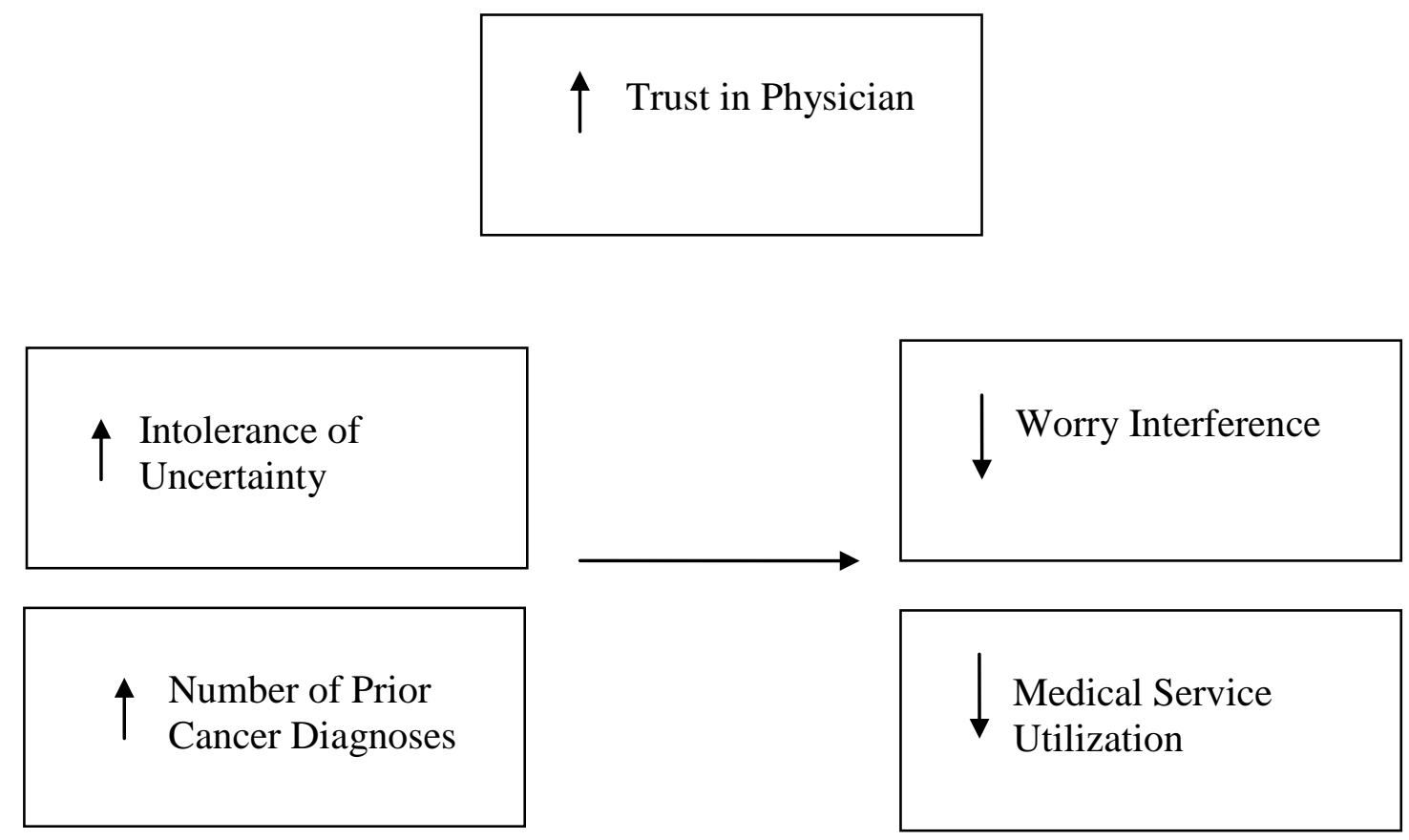

Figure 3. Aim 3: Hypothesized moderation of relationship between predictors (intolerance of uncertainty and prior cancer diagnosis) and outcomes (worry interference and medical service utilization) by trust in physician. 


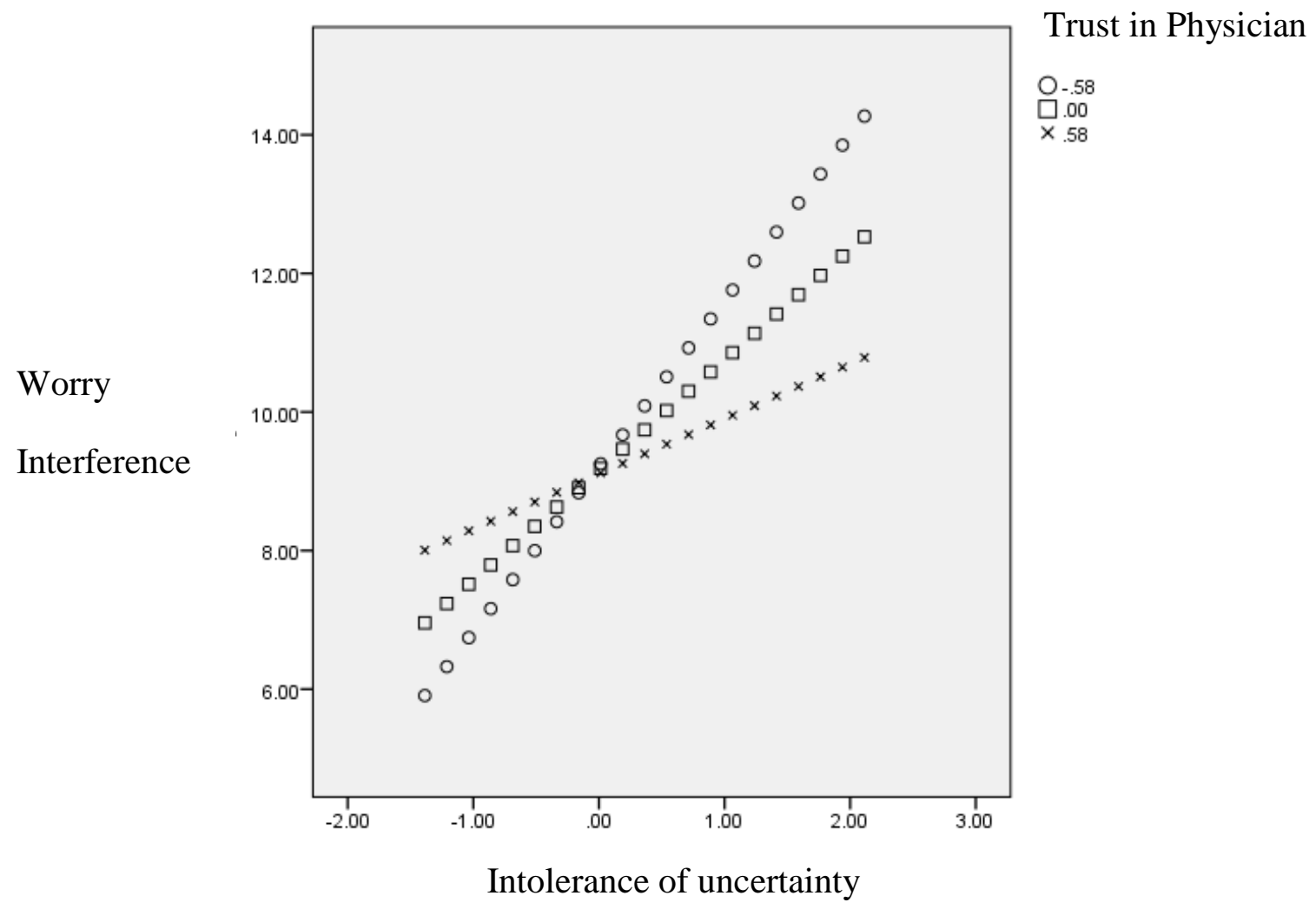

Figure 4. Trust in physician moderating the relation between intolerance of uncertainty and worry interference 
Appendix A.

\begin{tabular}{|c|c|c|c|c|c|}
\hline & Not at all & A little & Somewhat & Quite a bit & A lot \\
\hline $\begin{array}{l}\text { WIS1) Fears of developing cancer have } \\
\text { affected my relationships with others. }\end{array}$ & 0 & 1 & 2 & 3 & 4 \\
\hline $\begin{array}{l}\text { WIS2) Thoughts of Lynch syndrome have } \\
\text { affected my ability to sleep. }\end{array}$ & 0 & 1 & 2 & 3 & 4 \\
\hline $\begin{array}{l}\text { WIS3) I am able to talk to my partner } \\
\text { about my Lynch syndrome concerns. }\end{array}$ & 0 & 1 & 2 & 3 & 4 \\
\hline $\begin{array}{l}\text { WIS4) My partner is able to understand } \\
\text { my concerns. }\end{array}$ & 0 & 1 & 2 & 3 & 4 \\
\hline $\begin{array}{l}\text { WIS5) Thoughts of Lynch syndrome have } \\
\text { affected my work. }\end{array}$ & 0 & 1 & 2 & 3 & 4 \\
\hline $\begin{array}{l}\text { WIS6) I think about my } \\
\text { children's/grandchildren's chances of } \\
\text { developing cancer or Lynch syndrome. }\end{array}$ & 0 & 1 & 2 & 3 & 4 \\
\hline $\begin{array}{l}\text { WIS7) Concerns about Lynch syndrome } \\
\text { or cancer have affected my ability to have } \\
\text { fun. }\end{array}$ & 0 & 1 & 2 & 3 & 4 \\
\hline $\begin{array}{l}\text { WIS8) Fears of Lynch syndrome have } \\
\text { affected my ability to feel sexually } \\
\text { attractive. }\end{array}$ & 0 & 1 & 2 & 3 & 4 \\
\hline $\begin{array}{l}\text { WIS9) Worries about Lynch syndrome } \\
\text { have affected my ability to meet the needs } \\
\text { of my family. }\end{array}$ & 0 & 1 & 2 & 3 & 4 \\
\hline $\begin{array}{l}\text { WIS10) Lynch syndrome concerns have } \\
\text { affected my ability to concentrate. }\end{array}$ & 0 & 1 & 2 & 3 & 4 \\
\hline $\begin{array}{l}\text { WIS11) Cancer risks affected my decision } \\
\text { to have children. }\end{array}$ & 0 & 1 & 2 & 3 & 4 \\
\hline
\end{tabular}




\section{Appendix B.}

In the past six months, how many visits did you make to any of these health professionals?

\begin{tabular}{|c|c|c|c|c|}
\hline & Type of Health Professional & $\begin{array}{r}\text { Was th } \\
\text { schedu } \\
\text { (C) }\end{array}$ & $\begin{array}{l}\text { egularly } \\
\text { leck-up? } \\
\text { one) }\end{array}$ & $\begin{array}{c}\text { Number of } \\
\text { Visits }\end{array}$ \\
\hline$\square$ & Internist, Family Doctor, General Practitioner & Yes $\square$ & No $\square$ & \\
\hline$\square$ & Oncologist & Yes $\square$ & No $\square$ & \\
\hline$\square$ & Surgeon & Yes $\square$ & No $\square$ & \\
\hline$\square$ & Gastrointestinal (GI) Specialist & Yes $\square$ & No $\square$ & \\
\hline$\square$ & Cardiologist & Yes $\square$ & No $\square$ & \\
\hline$\square$ & Emergency Room Visit & Yes $\square$ & No $\square$ & \\
\hline$\square$ & Genetic Counsellor & Yes $\square$ & No $\square$ & \\
\hline$\square$ & Gynaecologist & Yes $\square$ & No $\square$ & \\
\hline$\square$ & Write in another specialist if not listed above: & Yes $\square$ & No $\square$ & \\
\hline
\end{tabular}




\section{Appendix C.}

The following statements describe how people may react to the uncertainties of life. Please circle a number ( 1 to 5 ) that best describes to what extent each item is characteristic of you.

IUS1) Unforeseen events upset me greatly.

3

4

5

Not at all characteristic of me

Somewhat characteristic of me

Entirely characteristic of me

IUS2) It frustrates me not having all the information I need.

1

Not at all characteristic of me
2

3

Somewhat characteristic of me
4

5

Entirely characteristic of me

IUS3) One should always look ahead so as to avoid surprises.

1 2

3

4

5

Not at all characteristic of me

Somewhat characteristic of me

Entirely characteristic of me

IUS4) A small, unforeseen event can spoil everything, even with the best of planning.

1 2

3

4 5

Not at all characteristic of me

Somewhat characteristic of me

Entirely characteristic of me

IUS5) I always want to know what the future has in store for me.

1 2

3

4

5

Not at all characteristic of me

Somewhat characteristic of me

Entirely characteristic of me

IUS6) I can’t stand being taken by surprise.

1 2

3

4

5

Not at all characteristic of me

Somewhat characteristic of me

Entirely characteristic of me

IUS7) I should be able to organize everything in advance.

1

2

3

4

5

Not at all characteristic of me

Somewhat characteristic of me

Entirely characteristic of me

IUS8) Uncertainty keeps me from living a full life. 
IUS9) When it's time to act, uncertainty paralyzes me.

1

Not at all characteristic of me
2

Somewhat characteristic of me
4 5

Entirely characteristic of me

IUS10) When I am uncertain, I can't function very well.

1

Not at all characteristic of me

\section{2}

3

Somewhat characteristic of me

\section{IUS11) The smallest doubt can stop me from acting.}

1

2

3

Somewhat characteristic of me

Not at all characteristic of me

IUS12) I must get away from all uncertain situations.

1

2

3

Not at all characteristic of me

Somewhat characteristic of me
4

5

Entirely characteristic of me

4

5

Entirely characteristic of me

4

5

Entirely characteristic of me 
Appendix D.

Have you ever been diagnosed with ANY type of cancer? $\quad \square$ Yes $\quad \square$ No

If yes, please answer the following:

\begin{tabular}{|l|l|}
\hline Type of Cancer You Were Diagnosed With & Age of Diagnosis \\
\hline & \\
\hline & \\
\hline & \\
\hline & \\
\hline & \\
\hline
\end{tabular}


Appendix E.

\begin{tabular}{|l|l|l|l|l|l|}
\hline & $\begin{array}{c}\text { Disagree } \\
\text { Very } \\
\text { Much }\end{array}$ & Disagree & $\begin{array}{c}\text { Neither } \\
\text { agree or } \\
\text { disagree }\end{array}$ & Agree & $\begin{array}{c}\text { Agree Very } \\
\text { Much }\end{array}$ \\
\hline $\begin{array}{l}\text { TPS1) I doubt that my family doctor } \\
\text { really cares about me as a person. }\end{array}$ & & & & & \\
\hline $\begin{array}{l}\text { TPS2) My family doctor is usually } \\
\text { considerate of my needs and puts } \\
\text { them first. }\end{array}$ & & & & & \\
\hline $\begin{array}{l}\text { TPS3) I trust my family doctor so } \\
\text { much that I always follow his/her } \\
\text { advice. }\end{array}$ & & & & & \\
\hline $\begin{array}{l}\text { TPS4) If my family doctor tells me } \\
\text { that something is so, then it must be } \\
\text { true. }\end{array}$ & & & & & \\
\hline $\begin{array}{l}\text { TPS5) I sometimes distrust my } \\
\text { family doctor's opinion and would } \\
\text { like a second one. }\end{array}$ & & & & & \\
\hline $\begin{array}{l}\text { TPS6) I trust my family doctors } \\
\text { judgments about my medical care. }\end{array}$ & & & & & \\
\hline $\begin{array}{l}\text { TPS7) I feel my family doctor does } \\
\text { not do everything he/she should for } \\
\text { my medical care. }\end{array}$ & & & & & \\
\hline $\begin{array}{l}\text { TPS8) I trust my family doctor to put } \\
\text { my medical needs above all other } \\
\text { considerations when treating my } \\
\text { medical problems. }\end{array}$ & & & & & \\
\hline $\begin{array}{l}\text { TPS9) My family doctor is a real } \\
\text { expert in treating medical problems } \\
\text { like mine. }\end{array}$ & & & & & \\
\hline $\begin{array}{l}\text { TPS10) I trust my family doctor to } \\
\text { tell me if a mistake was made about }\end{array}$ & & & & & \\
\hline
\end{tabular}




\begin{tabular}{|l|l|l|l|l|l|}
\hline my treatment. & & & & & \\
\hline TPS11) I sometimes worry that my & & & & & \\
family doctor may not keep the & & & & & \\
information we discuss totally & & & & & \\
private. & & & & & \\
\hline
\end{tabular}

